\title{
The Relationship between Kinesthetic Perceptions of Elite Music Theater Singers and Acoustic Measures of Voice Production Methods: A Pedagogic Analysis
}

Leigh Usilton

Follow this and additional works at: https://researchrepository.wvu.edu/etd

\section{Recommended Citation}

Usilton, Leigh, "The Relationship between Kinesthetic Perceptions of Elite Music Theater Singers and Acoustic Measures of Voice Production Methods: A Pedagogic Analysis" (2015). Graduate Theses, Dissertations, and Problem Reports. 6853.

https://researchrepository.wvu.edu/etd/6853

This Dissertation is protected by copyright and/or related rights. It has been brought to you by the The Research Repository @ WVU with permission from the rights-holder(s). You are free to use this Dissertation in any way that is permitted by the copyright and related rights legislation that applies to your use. For other uses you must obtain permission from the rights-holder(s) directly, unless additional rights are indicated by a Creative Commons license in the record and/ or on the work itself. This Dissertation has been accepted for inclusion in WVU Graduate Theses, Dissertations, and Problem Reports collection by an authorized administrator of The Research Repository @ WVU.

For more information, please contact researchrepository@mail.wvu.edu. 


\title{
The Relationship between Kinesthetic Perceptions of Elite Music Theater Singers and Acoustic Measures of Voice Production Methods: A Pedagogic Analysis
}

\author{
Leigh Usilton
}

\author{
Doctoral Essay submitted \\ to the College of Creative Arts \\ at West Virginia University \\ in partial fulfillment of the requirements for the degree of \\ Doctor of Musical Arts in \\ Vocal Pedagogy and Performance
}

Nicholas K. Perna, D.M.A., Chair

Travis Stimeling, Ph.D.

Robert Orlikoff, Ph.D.

Hope Koehler, D.M.A.

Michael Vercelli, D.M.A.

School of Music

Morgantown, West Virginia

2015

Keywords: Vocal Pedagogy, Music Theater, Belt, Mix, Legit, Singing Acoustics

Copyright 2015 Leigh Usilton 


\title{
ABSTRACT \\ The Relationship between Kinesthetic Perceptions of Elite Music Theater Singers and Acoustic Measures of Voice Production Methods: A Pedagogic Analysis
}

\author{
Leigh Usilton
}

This study relates acoustic changes that occur during female belt voice, mix voice, and legit voice to the self-reported physical sensations of elite music theater (MT) singers for the purposes of developing further pedagogic language to convey imagery and sensation to students of MT singing.

Six professional female MT singers comfortable producing belt, mix, and legit styles of singing sang a series of $\mathrm{C}$ major and E-flat major scales on the vowels /a/, /æ/, / / /, and / /, followed by three brief excerpts from the modern MT repertoire. Both prior to and following the sung exercises, subjects described the three styles based on their own kinesthetic feedback. Sung examples were recorded using spectrograph software and compared to the stated physical sensations of the singers.

The results of the study support the need for a MT specific pedagogy. Information provided by the six singers, both through interview and sung exercises, shows a clear difference between techniques they successfully use in the MT industry and those traditionally taught to classical singers. The results support the current literature on belt and mix techniques. In addition, a pattern in the acoustic spectrum of legit voice was found that shows a distinct difference between legit and classical styles of singing. Further research in this area is needed to clarify terminology used in the MT industry. 


\section{Acknowledgements}

Words cannot convey the gratitude I have for my mentor, Dr. Nicholas Perna. This project would not have been completed without your wisdom, guidance, and passion. Thank you Dr. Perna and Dr. Mandy Spivak for your loving support throughout this process. My sincere appreciation as well to my committee, Dr. Travis Stimeling, Dr. Hope Koehler, Dr. Robert Orlikoff, and Dr. Michael Vercelli, and to all of my past and present teachers and students at West Virginia University, Salisbury University, New York University, and Auburn University.

Thank you to those who participated in this study for your willingness to share your thoughts and talents.

Finally, I am grateful for the unconditional love of my family and friends. Thank you! 


\section{Table of Contents}

List of Tables

List of Figures vii

Chapter 1: Introduction and Need for the Study

Purpose of the Study 1

Introduction $\quad 1$

$\begin{array}{ll}\text { Need for the Study } & 6\end{array}$

Research Questions $\quad 9$

$\begin{array}{ll}\text { Definitions of Terminology } & 10\end{array}$

Chapter 2: Review of the Literature

Introduction and Limitations 13

$\begin{array}{ll}\text { Physiology } & 14\end{array}$

$\begin{array}{lr}\text { Acoustics } & 20\end{array}$

$\begin{array}{ll}\text { Perception } & 24\end{array}$

$\begin{array}{lr}\text { Terminology } & 28\end{array}$

Chapter 3: Method

$\begin{array}{ll}\text { Purpose } & 35\end{array}$

Subjects $\quad 35$

$\begin{array}{ll}\text { Materials } & 35\end{array}$

$\begin{array}{ll}\text { Procedure } & 36\end{array}$

$\begin{array}{ll}\text { Analysis } & 40\end{array}$ 
Chapter 4: Results

Introduction $\quad 41$

$\begin{array}{ll}\text { Subjects } & 41\end{array}$

Definitions 43

Acoustic Analysis $\quad 45$

Influence of Context and Character $\quad 54$

$\begin{array}{ll}\text { Exclusions } & 55\end{array}$

Chapter 5: Discussion

Advocating for MT Specific Pedagogy 56

Pedagogic Applications $\quad 59$

Areas of Future Research $\quad 62$

$\begin{array}{ll}\text { Bibliography } & 64\end{array}$

$\begin{array}{ll}\text { Appendix 1: Survey } & 69\end{array}$

$\begin{array}{ll}\text { Appendix 2: Informed Consent } & 70\end{array}$

$\begin{array}{ll}\text { Appendix 3: IRB Approval Letter } & 73\end{array}$

$\begin{array}{ll}\text { Appendix 4: Interview Transcripts } & 74\end{array}$ 


\section{List of Tables}

Table 1. Subject age and experience

Table 2. Years of training 


\section{List of Figures}

Figure 1. S3 E-flat scales in legit (Above) and belt (Below) 46

Figure 2. S4 $\mathrm{C}_{5}$ belt on /æ/, showing lack of release of $\mathrm{H} 4$ with a high $\mathrm{F}_{2}$

Figure 3. S2 $\mathrm{C}$ belt scale on /a/, showing lowered $\mathrm{F}_{1}$ from $\mathrm{B}_{4}$ Above to $\mathrm{C}_{5}$ Below 48

Figure 4. S1 C legit scale on / $/ / 29$

Figure 5. Above: S6 C mix scale on /o/; Below: S5 C mix scale on /o/ 50

Figure 6. Above: S3 E $b_{5}$ belt on /a/; Below: S2 E $b_{5}$ belt on /a/ 51

Figure 7. S1 Eb $b_{5}$ on /a/ 51

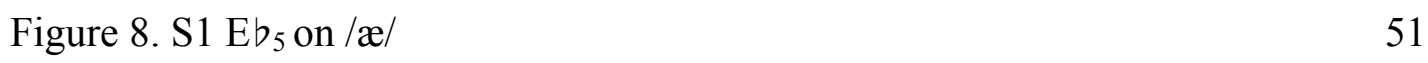

Figure 9. $\mathrm{S} 1 \mathrm{E} b_{5}$ on $/ \mathrm{J} /$

Figure 10. S2 E-flat belt scale on /a/, showing pivot note on $\mathrm{C}_{5}$

Figure 11. S3 E-flat legit scale on /a/ 53

Figure 12. S2 E-flat belt scale on /a/ 61 


\section{Chapter 1: Introduction and Need for the Study}

\section{PURPOSE OF THE STUDY}

The purpose of this study is to relate the acoustic changes that occur during female "belt" voice, "mix" voice, and "legit" voice to the self-reported physical sensations of elite music theater (MT) singers for the purposes of communicating specific terminology to voice teachers. The singers will describe kinesthetic feedback in these three methods common in Contemporary Commercial Music (CCM), a currently accepted term which includes multiple styles of nonclassical singing ("cabaret, country, experimental, folk, gospel, jazz, music theater, pop, rock, rhythm and blues"). ${ }^{1}$ Relating their descriptions to acoustic measures, a vocabulary will be developed with which teachers can further pedagogic language to convey imagery and sensation to their students.

\section{INTRODUCTION}

The pedagogic lexicon of Western classical singing has been developing for over 400 years, whereas the vocabulary and imagery for CCM teaching had its inception during the last century. Only since the 1970s have universities begun to add MT training to their traditionally classical programs. However, many of the teachers found in the academy were trained only in classical singing and pedagogy. ${ }^{2}$

\footnotetext{
${ }^{1}$ Edrie Means Weekly and Jeannette L. LoVetri, "Follow-Up Contemporary Commercial Music (CCM) Survey: Who's Teaching What in Nonclassical Music," Journal of Voice 23, no. 3 (2009): 367-75.

${ }^{2}$ Karen Hall, So You Want to Sing Music Theater: A Guide for Professionals (Lanham, Maryland: Rowman \& Littlefield, 2014).
} 
With an increasing number of universities adding MT degrees and programs, many of these classical teachers who lack formal training in CCM styles are being asked to teach in this style. ${ }^{3}$ In a recent Journal of Singing column, Scott McCoy points out that, "A perusal of recent vacancy notices in the academy shows a significant percentage searching for candidates with the ability to teach multiple genres equally well." He continues, "It is time to acknowledge that the world has changed, and that our curricula must be adapted to suit the needs and expectations of the real world, which includes skill in teaching both classical and CCM genres and techniques. Many schools have already jumped on the bandwagon."

Despite the addition of MT to university teaching, "many teachers who were trained only in classical vocal technique themselves admitted...to having no idea how to sing a piece of music in any other style,"5 according to a 2009 survey of teachers of singing (a follow-up to a survey from 2003). ${ }^{6}$ From the earlier survey, $34 \%$ of respondents teaching CCM at the university level "had neither professional experience nor university training (graduate, undergraduate, or noncredit). ${ }^{, 7}$ In the 2009 study, a total of 95 of the 145 respondents taught MT. Only 19\% of the 95 had been trained specifically in MT pedagogy, and only 7\% had both training and professional performance experience. Nearly one half of respondents had neither training nor

\footnotetext{
${ }^{3}$ Jeannette L. LoVetri, "The Confusion About Belting: A Personal Observation," NYSTA Voice Prints 10 (Sept.-Oct. 2012): 4-7.

${ }^{4}$ Scott McCoy, “Why I Don’t Teach Belting,” Journal of Singing 70, no. 2 (November/December 2013): $181-182$.

${ }^{5}$ Weekly and LoVetri, "Follow-Up Contemporary Commercial Music (CCM) Survey,” 373.

${ }^{6}$ Jeannette L. LoVetri and Edrie Means Weekly, "Contemporary Commercial Music (CCM) Survey: Who's Teaching What in Nonclassical Music,” Journal of Voice 17, no. 2 (June 2003): 207-15.

${ }^{7}$ Weekly and LoVetri, "Follow-Up Contemporary Commercial Music (CCM) Survey,” 367.
} 
experience in the MT style. The percentages are nearly the same for the 36 respondents who taught at colleges and universities. ${ }^{8}$

Even though recent research demonstrates differences between classical and CCM production in breathing and support, ${ }^{9}$ physiology, ${ }^{10}$ and resonance, ${ }^{11}$ nearly one third of university MT teachers "thought the approach was similar or there was no difference,"12 according to the 2003 survey. Though the 2009 survey showed an increasing number of teachers indicating they approached the teaching of the two styles differently, the majority of these differences were in musical style alone. ${ }^{13}$ Fortunately, from the survey data, the authors concluded "that most teachers desire to be more experienced in the teaching of CCM."14 Teachers actively sought education from CCM specialists through workshops, seminars, and private instruction. ${ }^{15}$

As with all voice pedagogy, the education of commercial styles will inevitably involve methods and terminology specific to CCM singing. The methods that will be examined in this study, "belt," "mix," and "legit," have been standard in casting notices for MT performers for

${ }^{8}$ Weekly and LoVetri, "Follow-Up Contemporary Commercial Music (CCM) Survey,” 370-372.

9 Johan Sundberg, Margareta Thalén, and Lisa Popeil, "Substyles of Belting: Phonatory and Resonatory Characteristics," Journal of Voice 26, no. 1 (January 2012): 44-50.

${ }^{10}$ Jo Estill, "Belting and Classic Voice Quality: Some Physiological Differences," Medical Problems of Performing Artists 3, no. 1 (1988): 37-43.

${ }^{11}$ Jeannette L. LoVetri, "Contemporary Commercial Music: More than One Way to Use the Vocal Tract," Journal of Singing 58 (January 2002): 249-252.

${ }^{12}$ Weekly and LoVetri, "Follow-Up Contemporary Commercial Music (CCM) Survey," 372-373.

${ }^{13}$ Weekly and LoVetri, "Follow-Up Contemporary Commercial Music (CCM) Survey,” 373.

${ }^{14}$ Weekly and LoVetri, "Follow-Up Contemporary Commercial Music (CCM) Survey,” 374.

${ }^{15}$ Weekly and LoVetri, "Follow-Up Contemporary Commercial Music (CCM) Survey," 371. 
years. ${ }^{16}$ The general understanding of these terms, however, does not match their frequency of use. Though producers, casting directors, and other industry professionals seek only their own perceptual idea of these terms as needed for their production, pedagogues must have a clear understanding of the physiological and acoustic definitions, in addition to a clear tonal idea of the perceptual style. Unfortunately, the perceptual, physiological, and acoustic definitions of these methods as presented in the research are confusing at best. The lack of clarity in their descriptions is partially due to the finding that a majority of teachers who teach CCM styles, even in university settings, have never trained in or performed the repertoire themselves. ${ }^{17}$

Defining "legit" is the clearest of the three terms. Legit, short for "legitimate," is a term most likely coined in the early 20th century describing those singers "who had received classical vocal training and could sing over an orchestra without strain." "Legit" is most similar to classical female singing though with a brighter sound. ${ }^{19}$ Because of this similarity, it is sometimes referred to as "classical" or "soprano" in current MT casting notices. ${ }^{20}$ Though little objective research has been performed specifically on "legit," as a term, a great deal of research has investigated classical female singing. This literature indicates that classical female singing is

\footnotetext{
${ }^{16}$ Jeannette L. LoVetri, “The Confusion About Belting: A Personal Observation," NYSTA Voice Prints 10 (September-October 2012): 4-7.

${ }^{17}$ Weekly and LoVetri, "Follow-Up Contemporary Commercial Music (CCM) Survey."

${ }^{18}$ American Academy of Teachers of Singing, "In Support of Contemporary Commercial (nonclassical) Voice Pedagogy," 2008.

${ }^{19}$ Julie E. Balog, “A Guide to Evaluating Music Theater Singing for the Classical Teacher," Journal of Singing 61, no. 4 (April 2005): 401-6.

${ }^{20}$ Warren Freeman, Kathryn Green, and Philip Sargent, “Deciphering Vocal Demands for Today’s Broadway Leading Ladies,” Journal of Singing 71, no. 4 (March-April 2015): 491-495.
} 
primarily mode two-dominant laryngeal registration. "Legit" singing differs from classical voice through raised formant frequencies resulting in a more "open" timbre. ${ }^{21}$

Stating a clear definition of belting, however, is more challenging. Part of the difficulty lies in the variety of uses of the same term. As LoVetri explains, "the word 'belter' is the description of someone who can sing in this vocal quality and is identified with it. The term 'belt' when applied to a song is an adjective. A 'belt song' is one that is meant to be sung in the vocal quality called 'belt.' You could be a belter, belting out a belt song." ${ }^{22}$ It is important to note that there are many sounds associated with belt among CCM styles, but it is generally described by MT professionals as being perceptually loud and bright with a clear, focused tone. ${ }^{23}$ Including more objective measurements, Kenneth Bozeman defines belting as "a singing style with a mode one-dominant laryngeal registration, using an acoustic strategy in which the first formant tracks the second harmonic; in other words, a kind of skillful yelling."24

Though a clear definition has not been agreed upon for "mix," recent research observed that though slightly different methods were used from singer to singer, physiological and acoustic measurements were found to be between those for "legit" and "belt." 25 It is often used in casting as a combination with another term: for example belt/mix, or head mix, indicating the perceptual sound desired for the role. ${ }^{26}$

${ }^{21}$ Kenneth W. Bozeman, Practical Vocal Acoustics: Pedagogic Applications for Teachers and Singers (Hillsdale, NY: Pendragon Press, 2013).

${ }^{22}$ LoVetri, "The Confusion About Belting," 4.

${ }^{23}$ Wendy DeLeo LeBorgne, Linda Lee, Joseph C. Stemple, and Heather Bush, "Perceptual Findings on the Broadway Belt Voice," Journal of Voice 24, no. 6 (November 2010): 678-89.

${ }^{24}$ Bozeman, Practical Vocal Acoustics, 103.

${ }^{25}$ Tracy Bourne, Maeva Garnier, and Diana Kenny, "Music Theater Voice: Production, Physiology and Pedagogy," Journal of Singing 67, no. 4 (April 2011): 1593.

${ }^{26}$ Freeman, Green, and Sargent, “Deciphering Vocal Demands for Today’s Broadway Leading Ladies.” 


\section{NEED FOR THE STUDY}

Historically, the most used vocal terminology is created by need. The terms "chest" and "head" voice, referring to the most often used registers in the singing voice were coined based on singer's perceptions of where they felt the sounds they were creating. Without the ability to see the vocal mechanism, teachers express function to students through vocabulary based on sensation. Though scientific fact is necessary for the informed pedagogue, empathy towards the singer's own perceptions is paramount in the form of an understandable terminology used in the studio environment.

In her book The Essentials of Singing, A Three-Step Kinesthetic Approach, Karen Tillotson Bauer describes a lack of connection between knowledge of voice science and its application in the studio among voice teachers, especially young ones. ${ }^{27}$ Bauer writes, "In no way minimizing the importance of voice science, concepts of vocal technique are applicable only if connected to the kinesthetic experience of singing, an experience of physical awareness and control." A solid knowledge and comprehension of voice function is necessary, although best used when it can be translated into applicable pedagogic vocabulary and techniques. The method she proposes "is based on the premise that the process of learning how to sing would benefit greatly from a terminology that is in close relationship to the language and sensations of the body. It seeks to foster the kinesthetic intelligence that enables fine singing.",28

With so many differences between classical and CCM singing, a new kinesthetic vocabulary must be established. A 2008 publication by The American Academy of Teachers of

\footnotetext{
${ }^{27}$ Karen Tillotson Bauer, The Essentials of Beautiful Singing: A Three-Step Kinesthetic Approach, (Lanham, Maryland: Scarecrow Press, 2013).

${ }^{28}$ Bauer, The Essentials of Beautiful Singing, 3.
} 
Singing, titled "In Support of Contemporary Commercial Music (nonclassical) Voice Pedagogy," clearly states the differences between classical and CCM voice, approaching it from both a historical and scientific perspective. With the knowledge available on the function of the human voice in these styles, and the technology available to continue research, AATS stated that the pedagogy community must accept that the two styles have "significant" acoustic and physiological differences that must be addressed in teaching them. ${ }^{29}$

LoVetri agrees, "As long as teachers of singing look for one kind of vocal behavior or one type of production, an impasse concerning contemporary commercial styles of singing will continue to exist. The many and varied technical requirements call for resourceful, creative use of vocal technique. ${ }^{30}$ She emphasizes that the demands on CCM singers are great, changing technique and style often not only within the same show, but even within a single song. ${ }^{31}$

With all of these possibilities, how does the teacher effectively communicate these changes to the student? Though these changes often occur in the moment of performance as an emotional response to the character, for the young student, or perhaps "crossover" artist who is new to the sensations of the MT style, there is need for an increased vocabulary involving kinesthetic feedback. Because of the wide variety of sounds exhibited in female MT singing, having similar terms for communicating sensation to belt and mix voice singers is necessary in the CCM voice studio.

${ }^{29}$ AATS, "In Support of Contemporary Commercial (nonclassical) Voice Pedagogy."

${ }^{30}$ Jeannette L. LoVetri, "Contemporary Commercial Music: More than One Way to Use the Vocal Tract," Journal of Singing 58 (January 2002): 251.

${ }^{31}$ LoVetri, "Contemporary Commercial Music: More than One Way to Use the Vocal Tract," 250. 
As stated earlier, with so many teachers teaching CCM without having performed the style or material themselves, ${ }^{32}$ it is logical to speak to those who are successful in the field in order to further the development of terminology that can be useful for teaching MT singers. "Ideally, we need research conducted in the field on professional belters of long standing who have a clear approach to the sound and who have been healthy....If you want to teach belting, or be a belter, be sure to talk to someone who is. Ask someone who understands what he or she is doing and can explain it in terms that make sense and that follow what we understand about vocal function." ${ }^{33}$ This study will survey and investigate elite, professional MT singers to provide voice teachers with new techniques and terminologies for teaching belt and mix voice in their studios. By comparing acoustic data collected from these MT performers to their perceptions and kinesthetic feedback of belt, mix, and legit singing, this study will expand the pedagogic lexicon related to these sensations.

\footnotetext{
${ }^{32}$ Weekly and LoVetri, "Follow-Up Contemporary Commercial Music (CCM) Survey."

${ }^{33}$ LoVetri, "Contemporary Commercial Music: More than One Way to Use the Vocal Tract," 7.
} 


\section{RESEARCH QUESTIONS}

What differences are present in the acoustics of elite MT singers while singing in "belt," "mix," and "legit" modes of production?

When elite MT singers are asked to produce tones in "belt" voice what are their acoustic properties?

When elite MT singers are asked to execute a phrase in "mix" voice what are the acoustic properties?

When elite MT singers are asked to execute a phrase in "legit" voice what are the acoustic properties?

How do elite MT singers describe the sensation of singing in "belt," "mix," and "legit" modes of production?

What is the relationship between elite MT singers' kinesthetic feedback (stated physical sensation) of "belt" voice and the acoustic properties of their sound?

What is the relationship between elite MT singers' kinesthetic feedback of "mix" voice and the acoustic properties of their sound?

What is the relationship between elite MT singers' kinesthetic feedback of "legit" voice and the acoustic properties of their sound? 


\section{DEFINITIONS}

belt voice: see chapter 2

chest voice: in the female voice, the traditional term for a mode-1 dominant laryngeal mechanism. Also the mechanism usually associated with belt singing in Contemporary Commercial Music. ${ }^{34}$

closed/contact quotient (CQ): the percentage of time the glottis is closed during one glottal cycle. A mode 1 laryngeal mechanism generally has a higher CQ than mode 2. It is measured using an electroglottograph, or EGG. ${ }^{35}$

Contemporary Commercial Music (CCM): a term coined by Jeannette LoVetri to move away from the term "nonclassical." It includes multiple styles, including cabaret, country, experimental, folk, gospel, jazz, music theater, pop, rock, rhythm and blues. ${ }^{36}$

cricothyroid (CT) muscle: one of the primary muscles of phonation. When contracted, it lengthens and thins the vocals folds, resulting in a raised pitch. The dominant muscle of mode 2 , or "head voice." 37

formant: a resonance of the vocal tract. The first two formants $\left(F_{1}\right.$ and $\left.F_{2}\right)$ are the vowel formants. A clustering of the third, fourth, and fifth formants is called the singer's formant. ${ }^{38}$

formant tracking: "the tuning of a formant to follow or track a specific harmonic,"39 for example the possible tuning of the first formant to the second harmonic $\left(\mathrm{F}_{1} / \mathrm{H} 2\right)$ in female belt.

formant tuning: in the singing voice, a tuning of the first and/or second formant to a harmonic in order to reach optimal resonance for the particular fundamental frequency. ${ }^{40}$

${ }^{34}$ Kenneth W. Bozeman, Practical Vocal Acoustics: Pedagogic Applications for Teachers and Singers, (Hillsdale, NY: Pendragon Press, 2013), 107-108.

${ }^{35}$ Ibid., 104.

${ }^{36}$ Edrie Means Weekly and Jeannette L. LoVetri, "Follow-Up Contemporary Commercial Music (CCM) Survey: Who's Teaching What in Nonclassical Music,” Journal of Voice 23, no. 3 (2009), 367.

${ }^{37}$ Bozeman, Practical Vocal Acoustics, 107-108.

${ }^{38}$ Donald G. Miller, Resonance in Singing: Voice Building through Acoustic Feedback, (Princeton, NJ: Inside View Press, 2008), 113-114.

${ }^{39}$ Bozeman, Practical Vocal Acoustics, 106.

${ }^{40}$ Miller, Resonance in Singing, 114. 
harmonics: the frequencies that make up the acoustic spectrum. A harmonic is either the fundamental frequency $\left(\mathrm{F}_{0}\right)$ or a whole number multiple of it. They are written as the multiple of the fundamental, therefore $\mathrm{F}_{0}=\mathrm{H} 1$, followed by $\mathrm{H} 2, \mathrm{H} 3, \mathrm{H} 4$, etc. ${ }^{41}$

head voice: in the female voice, the traditional term for a mode-2 dominant laryngeal mechanism. It is used for the majority of the female range in classical repertoire. Also associated with legit singing in music theater repertoire. ${ }^{42}$

legit voice: see chapter 2

mix voice: see chapter 2

modal register: in speech, the comparative term to chest voice. It represents the normal speech register for men and women. ${ }^{43}$

mode 1 (M1): a production defined by shorter, thicker vocal folds with a large vertical contact area and higher closed/contact quotient (CQ), leading to a large range of higher harmonics. Traditionally referred to as "chest" voice. ${ }^{44}$

mode 2 (M2): a laryngeal mechanism defined by cricothyroid (CT) dominant muscle use, a small, thin contact area, lower closed/contact quotient (CQ), and a steeper roll-off of high harmonics. Traditionally referred to as "head" voice. ${ }^{45}$

music theater (MT): A theatrical performance during which music plays a pivotal role in the storytelling.

passaggio: a traditional Italian designation of register transitions. Traditional female passaggi occur around $\mathrm{E}_{4}$ (primo passaggio) and about an octave higher at the top of the treble staff (secondo passaggio). Though the first aligns with a natural transition from mode 1 (chest voice) to mode 2 (head voice), the second is an acoustic register shift. ${ }^{46}$

register: a series of pitches that share a similar laryngeal mechanism and timbre. Laryngeal registration involves the use of the $\mathrm{CT}$ and TA muscles, timbre is a result of formant tuning. ${ }^{47}$

${ }^{41}$ Bozeman, Practical Vocal Acoustics, 107.

${ }^{42}$ Bozeman, Practical Vocal Acoustics, 108.

${ }^{43}$ Johan Sundberg, The Science of the Singing Voice, (Dekalb, IL: Northern Illinois University Press, 1987), 3 .

\footnotetext{
${ }^{44}$ Scott McCoy, Your Voice: An Inside View, $2^{\text {nd }}$ ed., (Delaware, OH: Inside View Press, 2012), 144.

${ }^{45}$ Ibid., 145.

${ }^{46}$ Ibid., 148-149.

${ }^{47}$ Bozeman, Practical Vocal Acoustics, 103, 107.
} 
roll-off: written in $\mathrm{dB} /$ octave, the drop in the intensity of harmonics after the fundamental. Also called "tilt." 48

source and filter: the waveform produced at the vocal folds, or the "source," (sometimes also used to refer to the vocal folds themselves) is "filtered" through the vocal tract, strengthening some harmonics and weakening others. ${ }^{49}$

sound pressure level (SPL): an objective measurement of the intensity of sound, measured in decibels $(\mathrm{dB})$. $^{50}$

subglottal pressure $\left(\mathbf{P}_{\text {sub }}\right.$ : the positive air pressure measured below the glottis. ${ }^{51}$

thyroarytenoid (TA) muscle: one of the primary muscles of phonation, which make up the body of the vocal folds. They are considered to be the dominant muscle group for "chest voice" or mode $1 .{ }^{52}$

vocal tract: the tube resonator between the glottis and the lips, can be referred to as the filter. ${ }^{53}$

whoop timbre: a formant/harmonic tracking of the first formant and the first harmonic $\left(\mathrm{F}_{1} / \mathrm{H} 1\right)$. Present in classical female head voice. ${ }^{54}$

voix mixte: a traditional French term for the range that is timbrally perceived to be between mode 1 (chest voice) and mode 2 (head voice); comparative term to "mix voice" in CCM styles. $^{55}$

yell timbre: a formant/harmonic tracking of the first formant and the second harmonic $\left(\mathrm{F}_{1} / \mathrm{H} 2\right)$ carried higher than normal in mode 1 , producing a loud, brassy timbre; often present in belt. ${ }^{56}$

\footnotetext{
${ }^{48}$ Ibid., 112.

${ }^{49}$ Ibid., 113.

${ }^{50}$ Miller, Resonance in Singing, 120.

${ }^{51}$ Sundberg, The Science of the Singing Voice, 16.

${ }^{52}$ Bozeman, Practical Vocal Acoustics, 108.

${ }^{53}$ Ibid., 113.

${ }^{54}$ Bozeman, Practical Vocal Acoustics, 79.

${ }^{55}$ Miller, Resonance in Singing, 123.

${ }^{56}$ Bozeman, Practical Vocal Acoustics, 79.
} 


\section{Chapter 2: Review of the Literature}

\section{INTRODUCTION AND LIMITATIONS}

The following is a review of the current literature on music theater (MT) physiology, acoustics, and terminology. Only published research which specifically addresses the female music theater voice is included. Research involving other CCM styles, for example jazz and country, is omitted. Furthermore, publications that only serve the purpose of expressing the opinion of the author, and are founded only on personal observation, have been excluded from this review. Because the majority of publications on MT voice prior to 1990 fall into this category, most are not included in this document, except for a few articles by Robert Edwin and Jo Estill, authors who still actively publish in this area. As this study focuses on singers in good vocal health that have recently performed professionally, and presumably stylistically correct, the few articles available on vocal health and pathologies of CCM singers are not part of this review.

This chapter is organized into three sections. The first section presents current research on the physiology of female MT singing. Publications on the acoustic characteristics of MT singing follow. The third section focuses on perceptual characteristics of MT singing. Finally, issues related to pedagogic terminology in CCM styles are discussed. 


\section{PHYSIOLOGY}

In order to clarify definitions of belt, mix, and legit singing, the CCM / MT community must first agree on their physiologic characteristics.

According to Nathalie Henrich, two laryngeal mechanisms are primarily used in the female singing voice. Mode 1 (M1), which is a thyroarytenoid (TA) muscle dominant production defined by thicker vocal folds with a large vertical contact area and high closed/contact quotient (CQ), leading to a large range of higher harmonics; and Mode 2 (M2), defined by cricothyroid (CT) dominant muscle use, a small, thin contact area and low CQ, and a steeper roll-off of high harmonics. In the singing community, these are more commonly referred to as "chest voice" and "head voice," respectively. ${ }^{1}$

"Legit" has a relatively clear and commonly accepted definition, both perceptually and physiologically. It is the closest to classical "head" voice, mainly in M2 production, though with a brighter sound. ${ }^{2}$

There is less clarity and agreement as to the exact function of the laryngeal mechanism in belt and mix singing. This is partially due to the lack of clearly stated definitions of the terms. Belt is either described as an extension of "chest voice"/ M1 past the usual break around E4/F4, or as an extension of the speaking voice, or "speaking mix."3 Most authors agree that "belt" is a higher use of M1 or "chest" voice than in classical singing, though not all agree on the health of

\footnotetext{
${ }^{1}$ Natalie Henrich, "Mirroring the Voice from Garcia to the Present Day: Some Insights into Singing Voice Registers," Logopedics Phoniatrics Vocology 31, no. 1 (February 2006): 3-14.

2 Julie A. Balog, “A Guide to Evaluating Music Theater Singing for the Classical Teacher," Journal of Singing 61, no. 4 (April 2005): 401-6.

${ }^{3}$ Norman Spivey, “Music Theater Singing...Let's Talk. Part 2: Examining the Debate on Belting," Journal of Singing 64, no. 5 (June 2008): 607-14.
} 
the mechanism when used in this manner for extended periods of time. ${ }^{4}$ Though both sides agree there is "chest"/M1 production, one group classifies it as an extreme, harmful use of the mechanism, while the other simply defines it as a healthy "chest-dominant" production. Since most female classical singers use M2 almost exclusively, many classically trained pedagogues are hesitant to accept a higher use of M1. Publications by Edwin, LoVetri, Popeil, and other singer/pedagogues agree that belt can be healthy, and point out that any technique when taken to an extreme can cause harm, operatic singing included. ${ }^{5}$

According to LoVetri, it is important to note that belting is not a register itself, but instead a method of singing. LoVetri writes the following:

Certain teachers have proposed that belting, which is simply the chest register quality carried up above the traditional E-F4 break at a loud decibel level, is a separate register unto itself. Research has strongly suggested that all register balance is a combination of cricothyroid and thyroarytenoid activity, and that, coupled with laryngeal height, vocal tract configuration, subglottic pressure, and transglottal airflow, is what the ear hears as tonal texture. Therefore, belting is just a label given to a certain aspect of chest register function. This definition is supported by decades of use in the theatrical community to characterize a specific type of singing and singer who could be heard at the back of a house long before there was electronic amplification.... ${ }^{6}$

She continues to say that professional CCM singers are able to sing with a light chest register, the same manner than classical singers can sing with a heavy head register. The "chest

\footnotetext{
${ }^{4}$ Spivey, "Music Theater Singing...Let's Talk."

5 Robert Edwin, “Belt Is Legit,” Journal of Singing 64, no. 2 (November 2007): 213-15; Jeannette L. LoVetri, "Female Chest Voice," Journal of Singing 60, no. 2 (December 2003): 161-64; Lisa Popeil, “The Multiplicity of Belting," Journal of Singing 64, no. 1 (October 2007): 77-80.

${ }^{6}$ Jeannette L. LoVetri, “Female Chest Voice,” Journal of Singing 60, no. 2 (December 2003): 162.
} 
register [M1] quality that is soft and light" ${ }^{\prime 7}$ is perhaps what is perceived in the MT community as "mix." Though it seems that most researchers agree that belt uses an M1 production, ${ }^{8}$ the literature suggests that the quality heard as "mix" is not created by a distinct laryngeal mechanism, but instead by a manipulation of the shape of the vocal tract. ${ }^{9}$ There is little research on "mix" in the MT / CCM voice, and as with many of the "belt" studies, they have used only a single subject. ${ }^{10}$ As this style seems to be individualized, greater research is needed in this area with a larger number of subjects.

In the female classical voice, the term voix mixte is often used, though the sound is quite different from MT mix. ${ }^{11}$ Studies in this area are more common than in CCM styles, and recent research does not support a blending of "belt" and "mix" in terms of laryngeal mechanism. ${ }^{12}$ It also conflicts with the recent conclusions of Kochis-Jennings et al., who suggest the possibility of four distinct physiological registers in MT singing. They found varying TA involvement, vocal process activity, and perceptual characteristics suggesting enough differentiation to

${ }^{7}$ Ibid.

${ }^{8}$ Tracy Bourne, Maeva Garnier, and Diana Kenny, "Music Theater Voice: Production, Physiology and Pedagogy," Journal of Singing 67, no. 4 (April 2011): 440-441.

${ }^{9}$ Ibid., 441.

${ }^{10}$ R.E. Stone, Thomas F. Cleveland, Johan Sundberg, and Jan Prokop, "Aerodynamic and Acoustical Measures of Speech, Operatic, and Broadway Vocal Styles in a Professional Female Singer," Journal of Voice 17, no. 3 (September 2003): 283-97; Johan Sundberg, Patricia Gramming, and Jeannette L. LoVetri, "Comparisons of Pharynx, Source, Formant, and Pressure Characteristics in Operatic and Musical Theatre Singing," Journal of Voice 7, no. 4 (1993): 301-10; Harm K. Schutte, and Donald G. Miller, "Belting and Pop, Nonclassical Approaches to the Female Middle Voice: Some Preliminary Considerations," Journal of Voice 7, no. 2 (June 1993): 142-50.

${ }^{11}$ Tracy Bourne and Maëva Garnier, "Physiological and Acoustic Characteristics of the Female Music Theater Voice," Journal of the Acoustical Society of America 131, no. 2 (February 2012): 1586-94.

${ }^{12}$ M. Castellengo, B. Chuberre, and N. Henrich, "Is 'voix mixte' the vocal technique used to smooth the transition across the two main laryngeal mechanisms, or an independent mechanism?" (Proceedings of ISMA, Nara, Japan, 2004). 
classify four registers instead of the traditional two: chest, chestmix, headmix, and head. ${ }^{13}$

Recent research by Karen Kochis-Jennings, et al. studied laryngeal muscle activity in commercial styles in "chest register," "head register," "chestmix," and "headmix." The authors refer to both chestmix and headmix as having "perceptual and acoustic characteristics...more similar to" chest register and head register, respectively. ${ }^{14}$

Though the quality of the tone can be perceived as "mixed" to the listener, singers are either singing in M1 or M2, while also adjusting their vocal tract so that the overall sound quality imitates that of the alternate mechanism. ${ }^{15}$ This is supported by LoVetri et al. who found that when singing in an MT “mix," professional music theater singers used a variety of physical adjustments in the vocal tract including varying laryngeal height; any sound described as "brighter" was created by some kind of shrinking of the vocal tract. ${ }^{16}$ They observed multiple configurations of the larynx, pharyngeal walls, soft palate, and oral/pharyngeal space in order to achieve the desired sound. This again is different from classical training, in that female classical singers aim to avoid registration and tonal shifts. ${ }^{17}$ Surveying how singers perceive these changes will help teachers find the most efficient manner of communicating the creation of the CCM sound.

${ }^{13}$ Karen Ann Kochis-Jennings, Eileen M. Finnegan, Henry T. Hoffman, and Sanyukta Jaiswal, "Laryngeal Muscle Activity and Vocal Fold Adduction During Chest, Chestmix, Headmix, and Head Registers in Females," Journal of Voice 26, no. 2 (March 2012): 183.

${ }^{14}$ Kochis-Jennings et al., "Laryngeal Muscle Activity and Vocal Fold Adduction During Chest, Chestmix, Headmix, and Head Registers in Females," 187.

15 Tracy Bourne, Maeva Garnier, and Diana Kenny. "Music Theater Voice: Production, Physiology and Pedagogy," Journal of Singing 67, no. 4 (April 2011): 441; Harm K. Schutte and Donald G. Miller, "Belting and Pop, Nonclassical Approaches to the Female Middle Voice: Some Preliminary Considerations." Journal of Voice 7, no. 2 (June 1993): 142-50.

${ }^{16}$ Jeannette L. LoVetri, Susan Lesh, and Peak Woo, "Preliminary Study on the Ability of Trained Singers to Control the Intrinsic and Extrinsic Laryngeal Musculature," Journal of Voice 13, no. 2 (June 1999): 219-26.

${ }^{17}$ Jeannette L. LoVetri, "Contemporary Commercial Music: More than One Way to Use the Vocal Tract," Journal of Singing 58 (January 2002): 249-52. 
Most studies in MT and CCM styles have similarly concluded that there are many ways to achieve the belt/mix sound. A recent study by Bourne and Garnier on MT singing compiled a review of the current research. They found that the most common findings include a high (as compared to classical) larynx, ${ }^{18}$ a constricted pharynx, ${ }^{19}$ a raised tongue, ${ }^{20}$ and a megaphone mouth shape. ${ }^{21}$ Though these are not the only possibilities, ${ }^{22}$ they are the most common findings in the literature. Despite differences in the specific methods, all of these studies agree, as LoVetri concluded, that a shortening of the vocal tract is necessary to achieve the brighter sound that accompanies most MT singing.

A higher subglottal pressure ${ }^{23}$ accompanied by a higher degree of glottal adduction ${ }^{24}$ has also been described in belt. Schutte and Miller included these qualities in their definition of belt: "Belting is a manner of loud singing that is characterized by consistent use of 'chest' register 558

${ }^{18}$ Ingo Titze, "Belting and a High Larynx Position,” Journal of Singing 63, no. 5 (May-June 2007): 557-

Johan Sundberg, Patricia Gramming, and Jeannette L. LoVetri, "Comparisons of Pharynx, Source, Formant, and Pressure Characteristics in Operatic and Musical Theatre Singing," Journal of Voice 7, no. 4 (1993): 301-10; Jo Estill, "Belting and Classic Voice Quality: Some Physiological Differences," Medical Problems of Performing Artists 3, no. 1 (1988): 37-43; V. Lawrence, "Laryngological Observations on 'Belting," Journal of Research In Singing, 1979.

${ }^{19}$ Sundberg et al., "Comparisons of Pharynx, Source, Formant, and Pressure Characteristics in Operatic and Musical Theatre Singing."

${ }^{20}$ Estill, "Belting and Classic Voice Quality: Some Physiological Differences”; Lawrence, "Laryngological Observations on "Belting"; LoVetri et al., "Preliminary Study on the Ability of Trained Singers to Control the Intrinsic and Extrinsic Laryngeal Musculature."

${ }^{21}$ Ingo Titze, Albert S. Worley, and Brad H. Story, "Source-Vocal Tract Interaction in Female Operatic Singing and Theater Belting,” Journal Of Singing 67, no. 5 (May-June 2011): 561-572.

${ }^{22}$ LoVetri found a few subjects who did not raise their larynx and who maintained a wide pharynx during a belt quality. LoVetri, "Preliminary Study on the Ability of Trained Singers to Control the Intrinsic and Extrinsic Laryngeal Musculature."

${ }^{23}$ Eva Björkner, Johan Sundberg, Tom Cleveland, and Ed Stone, "Voice Source Differences Between Registers in Female Musical Theater Singers," Journal of Voice 20, no. 2 (June 2006): 187-97. Sundberg et al., "Comparisons..."; Schutte and Miller, "Belting and Pop."

${ }^{24}$ Titze et al., "Source-Vocal Tract Interaction," 561; Schutte and Miller, "Belting and Pop"; Estill, "Belting and Classic Voice Quality." 
( $>50 \%$ closed phase of glottis) in a range in which larynx elevation is necessary to match the first formant with the second harmonic on open (high $\mathrm{F}_{1}$ ) vowels, that is, $\sim \mathrm{G}_{4}-\mathrm{D}_{5}$ in female voices.",25 In an effort to clarify this definition, Lebowitz and Baken studied CQ and SQ (speed quotient) in 20 singers. They found that "mean CQ for both styles [belt and legit] fell at or below 50\%,"26 and concluded that Schutte and Miller's claims were not universally true. Their findings about belt were actually close to Schutte and Miller's, however, the average CQ for belt in Lebowitz and Baken's study was $48.53 \% .{ }^{27}$ In a study regarding intrinsic and extrinsic musculature in belt, LoVetri concluded that this change could simply be attributed to the training of the singers. ${ }^{28}$ These elements are not universal or exclusive, however:

In a contemporary pop/rock Broadway show, the larynx may ride up and down, the pharynx way widen and narrow, the tongue may flatten or rise consistently higher in the back of the mouth, and the configuration of the vocal folds could go from thick to thin and from short to long, from pressed to relaxed, all very rapidly. There could be almost none, a little, or a lot of constriction in the pharyngeal space, and the tone could be anything from nasal to breathy. Further, the breath could be issued quickly or slowly, vigorously or gently, depending on the sound itself. Demands on the singer's technical versatility vary from show to show, within a show, or even within one song. ${ }^{29}$

${ }^{25}$ Schutte and Miller, "Belting and Pop," 147.

${ }^{26}$ Amy Lebowitz, and R. J. Baken, "Correlates of the Belt Voice: A Broader Examination," Journal of Voice 25, no. 2 (March 2011): 163.

${ }^{27}$ Lebowitz and Baken, "Correlates of the Belt Voice."

${ }^{28}$ Ibid.

${ }^{29}$ Jeannette L. LoVetri, “The Confusion About Belting: A Personal Observation,” NYSTA Voice Prints 10 (September-October 2012): 4-7. 
A great example of this is the song, "The Girl in 14G," a commonly performed cabaret

showpiece by Jeanine Tesori which has the singer performing MT, jazz, and classical in the same song. ${ }^{30}$ Because of the multitude of options available, teachers must have a clear understanding of the physiological and acoustic changes in the singing voice in order to effectively communicate these productions to students.

\section{ACOUSTICS}

The physiological characteristics described above support the acoustic findings in recent research, though there is debate as to whether the voice source or the vocal tract (or filter) is more important in achieving the perceptual goal. Although one group believes that it is the shape of the filter as described above that creates the belt/mix sound, some of the most recent scientific research points more towards the voice source as the determining factor, rather than formant tuning within the vocal tract. Subscribing to the filter theory, McCoy speculates that "high closed quotients help produce a glottal buzz with increased amplitude in high harmonics" ${ }^{\text {31 }}$ and a "shortened vocal tract through spreading the lips in a horizontal vowel position or slight elevation of the larynx" ${ }^{\prime 2}$ assists in the production of MT belt. Sundberg's conclusions are in direct contrast to thoughts provided by McCoy and Edwin. He concluded from his data that glottal parameters including CQ "separated the different styles more or less clearly.",33

\footnotetext{
${ }^{30}$ Balog, "Guide to Evaluating MT Singing."

${ }^{31}$ Scott McCoy, “A Classical Pedagogue Explores Belting,” Journal of Singing 63, no. 5 (June 2007): 548.

${ }^{32}$ McCoy, “A Classical Pedagogue Explores Belting,” 548.

33 Johan Sundberg, Margareta Thalén, and Lisa Popeil, "Substyles of Belting: Phonatory and Resonatory Characteristics," Journal of Voice 26, no. 1 (January 2012): 50.
} 
The one element on which both groups agree is that MT (and CCM in general) singers maintain consistently higher formant frequencies than classical singers. ${ }^{34}$ All MT research regarding formant tuning currently focuses on the first formant; there is no published research to date on the tuning of formant frequencies beyond $\mathrm{F}_{1} \cdot{ }^{35}$ Similar to the varied findings in physiological research, there are multiple acoustic strategies possible in production of the desired MT sound. Also similar to the above research, many studies have been based on a single-subject, so results are not conclusive. ${ }^{36}$

Legit has been found to have two possible formant tuning strategies, one that is similar to classical female singing, $\mathrm{F}_{1} / \mathrm{H} 1$, and another closer to belt, raising the first formant to track $\mathrm{H} 2$, but in a different laryngeal mechanism. ${ }^{37}$ It is these higher formant frequencies that create the brighter sound in MT singing.

The second strategy, when used with a M1 laryngeal mechanism, is what Bozeman calls “yell timbre," leading to his definition of belt as "a modified, skillful, and--when properly done-healthy form of the yell acoustic strategy.",38 The "yell" to which Bozeman refers is a tuning

\footnotetext{
${ }^{34}$ Eva Björkner, "Musical Theater and Opera Singing-Why So Different? A Study of Subglottal Pressure, Voice Source, and Formant Frequency Characteristics," Journal of Voice 22, no. 5 (September 2008): 533-40; R.E. Stone, Thomas F Cleveland, Johan Sundberg, and Jan Prokop, "Aerodynamic and Acoustical Measures of Speech, Operatic, and Broadway Vocal Styles in a Professional Female Singer," Journal of Voice 17, no. 3 (September 2003): 283-97; Martine E. Bestebreurtje and Harm K. Schutte, "Resonance Strategies for the Belting Style: Results of a Single Female Subject Study," Journal of Voice 14, no. 2 (June 2000): 194-204; Sundberg et al., "Comparisons..."

${ }^{35}$ Tracy Bourne and Maëva Garnier, "Physiological and Acoustic Characteristics of the Female Music Theater Voice in 'Belt' and 'Legit' Qualities," Proceedings of the International Symposium on Music Acoustics (Associated Meeting of the International Congress on Acoustics), Sydney and Katoomba, Australia, August 25-31, 2010.

${ }^{36}$ Sundberg et al., "Substyles of Belting"; Titze et al., "Source-Vocal Tract Interaction"; Stone et al., "Aerodynamic and Acoustical Measures"; Bestebreurtje and Schutte, "Resonance Strategies for the Belting Style"; Sundberg et al., "Comparisons..."; Schutte and Miller, "Belting and Pop"; Estill, "Belting and Classic Voice Quality."

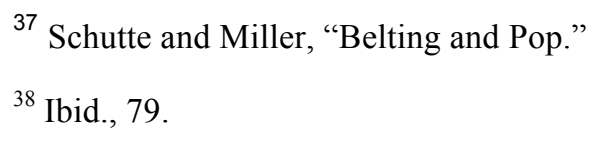


strategy that uses "a strong $\mathrm{F}_{1}$ tracking of $\mathrm{H} 2$ above the normal frequency of $\mathrm{F}_{1}$ for the vowel(s) in question." This creates a sound that is "powerful, usually clear, high in energy, expressive, and emotionally strong." 39 The findings of Schutte and Miller agree with these statements. ${ }^{40}$

Lebowitz and Baken's later study found less consistency in the $\mathrm{H} 2$ tuning. In the 20 singers studied, $70 \%$ of the singers maintained a higher $\mathrm{H} 1$, while only $30 \%$ showed a higher $\mathrm{H} 2$ indicative of a tuning to the raised $F_{1}$. The results were equally inconsistent in 15 of the 20 singers, who studied with the same teacher. They conclude that, "an upward extension of the modal [M1] register frequency range implies that register transition might not be 'disguised' but rather suppressed." ${ }^{41}$ This is similar to the findings of Sundberg et al. ${ }^{42}$

Scott McCoy offers a slightly different explanation - he credits the presence of more and higher harmonics, not necessarily specific formant tuning. McCoy observed, upon studying students of Robert Edwin, “in belt, strong harmonics are found through $10 \mathrm{kHz}$; in head voice, harmonics above $4 \mathrm{kHz}$ are relatively weak. It is interesting to note that the first two harmonics are actually stronger in head voice than in belting. ${ }^{, 43}$ He also notes that classical singing has "clear formant zones," whereas "the acoustic spectrum of belting is broader with formant regions that are less clearly defined."

Another important element of the acoustic qualities of belting is the vowels used. The vowel shapes are consistently wider and more likened to the shape of a "megaphone" than in

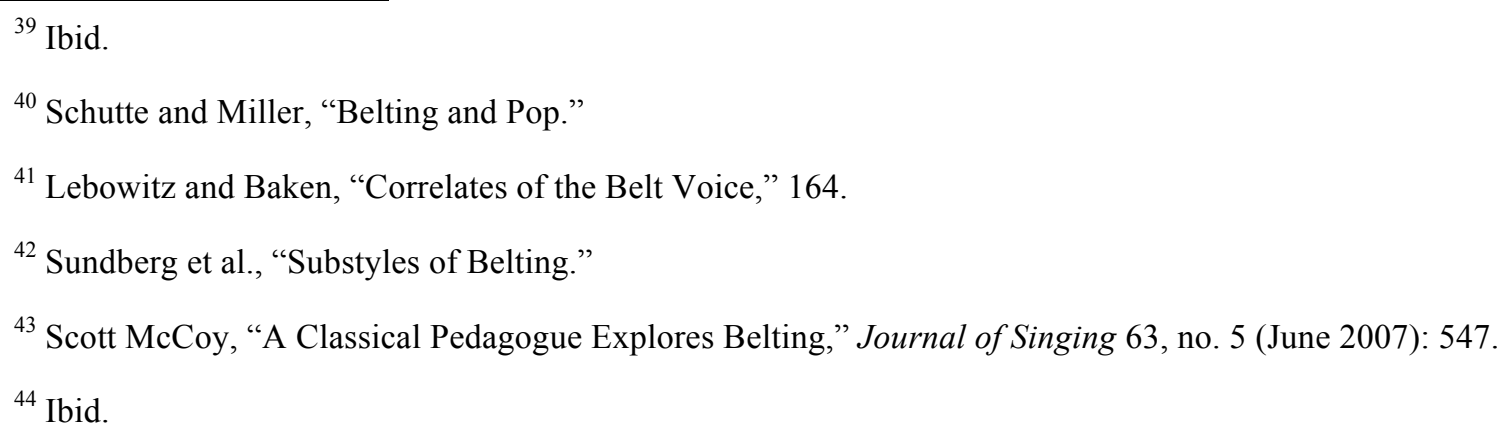


"operatic singing, ${ }^{45}$ resulting in higher formant frequencies. Stone et al. found that belters generally avoid vowels with low first formants (for example /i/ and /u/). This study used a single subject (co-author Prokop). They agreed with the findings of Schutte and Miller stating "that a strong second harmonic is the defining characteristic of the belt production." ${ }^{, 46}$

Another single subject study by Bestebreurtje and Schutte (2000) studied resonance qualities in belting for specific vowels: $/ \varepsilon /, / \mathrm{a} /, / \mathrm{i} /$, and $/ \mathrm{u} /$. They observed that " $/ \mathrm{a} /$ is inherently suitable for belting and requires no adjustment. For $/ \varepsilon /, \mathrm{F}_{2}-\mathrm{H} 5$ tuning was observed. For $/ \mathrm{i} /, \mathrm{F}_{1}$ was de-tuned from $\mathrm{H} 1$, enhancing also $\mathrm{H} 2$. For $/ \mathrm{u} /$, both $\mathrm{F}_{1}$ and $\mathrm{F}_{2}$ were raised to accomplish $\mathrm{F}_{2} / \mathrm{H} 3$ tuning. These results show that the loud, bright sound of the belting style is achieved by the implementation of resonance strategies that enhance higher harmonics." ${ }^{47}$

Because mix voice is frequently defined as having characteristics from both legit and belt voice, without clearly defined acoustic parameters in the belt sound, it is even more difficult to create defined acoustic qualities for mix. A 1993 single subject study found that mix, similar to belt, had greater high harmonics and raised first and second formant frequencies, however, subglottal pressure and sound pressure level (SPL) was found to be closer to classical singing. ${ }^{48}$ Sundberg et al. explored "mix" with LoVetri as their single subject, and though Stone et al. did not use the term "mix," their descriptions of a "Broadway vocal style" that was "not belting" is most likely similar to what is now called an MT mix style. ${ }^{49}$ They (Stone et al.) explained that there were samples their subject identified as "belting," however it was not used

\footnotetext{
${ }^{45}$ Stone et al., "Aerodynamic and Acoustical Measures"; Titze et al., "Source-Vocal Tract Interaction."

${ }^{46}$ Stone et al., "Aerodynamic and Acoustical Measures," 569.

${ }^{47}$ Bestebreurtje and Schutte, "Resonance Strategies for the Belting Style," 194.

${ }^{48}$ Sundberg et al., "Comparisons."

${ }^{49}$ Stone et al., "Aerodynamic and Acoustical Measures," 292.
} 
exclusively. ${ }^{50}$ Because the terminology is not consistently matched with perception by all teachers of this style, more than one tuning strategy is possible when performing in "mix."

Bourne and Garnier's 2012 study is one of the only studies to address the mix quality specifically in MT singing. They conclude "for all three singers, glottal and vocal tract measurements in mix quality were indeed observed at values in between those measured for legit and chesty belt qualities. However, each singer adopted different strategies to achieve this outcome." ${ }^{51}$ The first singer showed no $\mathrm{F}_{1} / \mathrm{H} 2$ tuning in mix, and showed $\mathrm{F}_{2}$ frequencies "between legit and belt values but closer to legit." $" 52$ The next two singers showed similar glottal behavior, but again different resonance strategies. Of these two, one showed similar qualities to her belt, utilizing $\mathrm{F}_{1} / \mathrm{H} 2$ tuning up to $\mathrm{A}_{4}$, with $\mathrm{F}_{2}$ frequencies closer to her belt values; the other was consistently closer to legit, with $\mathrm{F}_{2}$ frequencies closer to legit and no tuning to $\mathrm{F}_{1}{ }^{53}$

\section{PERCEPTION}

As is evident in the literature involving physiological and acoustic characteristics of MT singers, there are many opinions as to how these styles are produced, especially belt and mix. Much of the literature bases definitions of MT on perception alone and is written "from the inside, ${ }^{, 54}$ with classical singers and teachers not truly understanding the different pedagogic

\footnotetext{
${ }^{50}$ Ibid.

${ }^{51}$ Bourne and Garnier, "Physiological and Acoustic Characteristics," 1593.

52 Ibid.

53 Ibid.

${ }^{54}$ Norman Spivey, "Music Theater Singing...Let's Talk. Part 2: Examining the Debate on Belting," Journal
} of Singing 64, no. 5 (June 2008): 607-14. 
methods needed for CCM and MT styles of singing. ${ }^{55}$ Most current perceptual definitions of belt and MT styles are written from a classical perspective, using traditional classical terminology.

Scott McCoy warns against this approach. In his first studies of belt voice, he found all of the assumptions he had as a classical pedagogue were incorrect after observing students of Robert Edwin, a prominent teacher of belt and mix technique who has written extensively on the subject through his "Bach to Rock" column in Journal of Singing, as well as other publications. ${ }^{56}$ McCoy says that prior to these observations, he "had neither a valid tonal concept of contemporary belting nor a correct understanding of the physical processes involved in its production." 57

In 1990, Miles and Hollien attempted to create a definition of belt using the literature current to them as well as a survey of "individuals whom [they] considered knowledgeable in this area." ${ }^{58}$ They were careful to state the difference between a description, that which is perceived, and a definition, which has more basis in function. Combining these terms, they said, "belting can be described as a mode of singing that is typified by unusually loud, heavy phonation that exhibits little-to-no vibrato but a high level of nasality." 59 There is a lack of clarity in this type of comparative definition in its use of subjective descriptions like "unusually loud" that carry a negative connotation for the style being described.

${ }^{55}$ Edrie Means Weekly and Jeannette L. LoVetri, "Follow-Up Contemporary Commercial Music (CCM) Survey: Who's Teaching What in Nonclassical Music," Journal of Voice 23, no. 3 (2009): 367-75; Jeannette L. LoVetri and Edrie Means Weekly, “Contemporary Commercial Music (CCM) Survey: Who's Teaching What in Nonclassical Music,” Journal of Voice 17, no. 2 (June 2003): 207-15.

${ }^{56}$ Robert Edwin, "Belt Is Legit," Journal of Singing 64, no. 2 (November 2007): 213-15; Robert Edwin, "Belting 101," Journal of Singing 55 (September 1998): 53-55; Robert Edwin, "Belting 101, Part Two," Journal of Singing 55 (November 1998): 61-62.

${ }^{57}$ Scott McCoy, “A Classical Pedagogue Explores Belting,” Journal of Singing 63, no. 5 (June 2007): 548.

${ }^{58}$ Beth Miles and Harry Hollien, “Whither Belting?” Journal of Voice 4, no. 1 (1990): 69.

${ }^{59}$ Miles and Hollien, "Whither Belting?” 69. 
Since this was published, several have attempted to clarify this definition using less subjective words. In a 2009 study titled "Perceptual Findings on the Broadway Belt Voice" by Wendy LeBorgne, Linda Lee, Joseph C. Stemple, and Heather Bush, the authors surveyed casting directors to "evaluate the belt voice quality" of MT majors who have studied this style. The authors aimed to further clarify perceptual definitions of the belt voice using the definition created by Miles and Hollien with additional terms used by pedagogues Scott $\mathrm{McCoy}^{60}$ and Robert Edwin. ${ }^{61}$ LeBorgne states that in order to properly define belting, an agreement must be reached among pedagogues as to the aesthetically pleasing characteristics of the style. Questions were posed to the participants regarding the four qualities defined by Miles and Hollien (loudness, vibrato, nasality, and perception of "ring," or placement of voice), as well as defining a "noticeable passaggio," and tone and timbre.

Based on the listeners' perceptual analyses, singers were rated as poor, average, and elite belters. Several of Miles and Hollien's terms were disputed, including loudness and lack of vibrato. This survey is different than most others in that it asks opinions of its singer participants, though only related to sensations in their own voice. They were asked "Do you feel that you have a noticeable 'break'/passaggio? If so where does it occur?"62 Aside from this one personal question, they were asked similar questions to those asked of the three expert reviewers. Those surveyed found "ring and vibrato" to be the "most deciding perceived events to characterize the elite belt voice. Loudness also showed a strong correlation to ring and vibrato, perhaps

\footnotetext{
${ }^{60}$ McCoy, "Classical Pedagogue Explores Belting."

${ }^{61}$ Edwin, "Belting 101 Part 2."

${ }^{62}$ Wendy DeLeo LeBorgne, Linda Lee, Joseph C. Stemple, and Heather Bush, "Perceptual Findings on the Broadway Belt Voice," Journal of Voice 24, no. 6 (November 2010): 678-89.
} 
influencing the overall perception of the elite student belt sound." ${ }^{63}$ Perception of "timbre, focus/clarity, nasality, and registration" was not statistically significant among the students and judges. ${ }^{64}$

More recently, LoVetri addressed the same four elements of Miles and Hollien's definition: loudness, vibrato, nasality, and heavy phonation, presented as an aspect of registration. She clarifies that an understanding of registration is necessary to employ and teach this style, and that it is "an important aspect of vocal function" unlike many classical pedagogies. ${ }^{65}$ LoVetri attempts to dispel the following misconceptions regarding belting: the "edgy brightness" is nasality, the loud volume is "only shouting" and that all belting is produced with a straight tone, stating, "contrary to popular belief, [it] often has a strong steady vibrato."66 LoVetri's definition continues: “...the most consistent ingredients in belting are that it is "chest register' or TA dominant, it's loud, it 'carries' and it has elements of speech production through all but perhaps the highest pitches, and it doesn't 'kick in' as belting until it is near or above the traditional 'break' or 'passaggio."”67

There are many different ways to sing MT repertoire and many different acceptable sounds. This is why the previously discussed objective research was inconclusive as a whole. How can an encompassing definition of a continually varying medium be created? Current

\footnotetext{
${ }^{63}$ LeBorgne et al., 682.

${ }^{64}$ Ibid.

${ }^{65}$ LoVetri, "The Confusion About Belting."

${ }^{66}$ Ibid.

${ }^{67}$ LoVetri, "The Confusion About Belting."
} 
Broadway trends show a majority of roles requiring pop/rock and belt sounds, ${ }^{68}$ but older shows are constantly revived on Broadway, in touring companies, and regional and local theater.

Because the goal of MT singers is to most effectively communicate text and character, a large range of sounds is required for today's MT singers. ${ }^{69}$ This explains the confusion among voice teachers, especially those with primarily classical backgrounds in which a consistent sound through registers is common practice. ${ }^{70}$

\section{TERMINOLOGY}

Though perceptual definitions are useful in communicating the desires of the music theater industry to the performers seeking work, "[ $[\mathrm{t}]$ he usefulness of a term depends on the extent to which it means the same thing to different people."

To break away from classical terminology, some have created their own terminology and/or teaching methods, adding more confusion. Some of these include The Estill Voice Model, Somatic Voicework ${ }^{\mathrm{TM}}$, The LoVetri Method, Vocal Power Academy (Elisabeth Howard), Speech Level Singing Method (Seth Riggs), Bel Canto Can Belto (Mary Saunders-Barton), and Voiceworks (Lisa Popeil). ${ }^{72}$

\footnotetext{
${ }^{68}$ Warren Freeman, Kathryn Green, and Philip Sargent, “Deciphering Vocal Demands for Today's Broadway Leading Ladies," Journal of Singing 71, no. 4 (March-April 2015): 491-495.

${ }^{69}$ Jeannette L. LoVetri, "Contemporary Commercial Music: More than One Way to Use the Vocal Tract," Journal of Singing 58 (January 2002): 249.

${ }^{70}$ American Academy of Teachers of Singing, "In Support of Contemporary Commercial (nonclassical) Voice Pedagogy," 2008.

${ }^{71}$ Lebowitz and Baken, "Correlates of the Belt Voice," 164.

${ }^{72}$ Hall, So You Want to Sing Music Theater, 75.
} 
Lisa Popeil breaks down MT belting into five styles, determined by the difference in timbre of each sound. She labels them "heavy belt, nasal belt, twangy belt, brassy belt, and speech-like belt." ${ }^{, 73}$ The difficulty in using Popeil's labels, and other methods like hers, is that they are purely sonic in nature and not based on physiological or acoustic differences. Sundberg, Thalen, and Popeil attempted to quantify phonatory and resonatory characteristics of the styles of belting as described by Popeil: "heavy," "brassy," "ringy" (earlier called twangy), "nasal," and “speech-like." These were performed by Popeil as the single subject. Because they were her definitions of her personal sensations of belt, there is still a level of subjectivity to the study. ${ }^{74}$

Given their own vocabulary within their descriptions, the authors are able to state their opinions as well. To create a clear definition, the terms need to be more universally defined using objective data. LoVetri aims to end the debate by coming to a consensus as to what belting, in physiological and acoustic terms, means.

If we were all agreeable and sought to find science-based words that explained long-held and highly regarded pedagogical terms, we would be moving in a good direction. In the case of belting, however, there are no such traditions to guide us, except for words found in the marketplace. We are left with a hodge-podge of ideas about production and aesthetics that leaves each teacher alone with his or her own approach. This does not move the profession easily into the 21 st century. When vocal pedagogy can be hooked to vocal function as understood in voice science, the entire profession will be better off. Then, the terminology can be more standardized and this will help both singers and teachers share useful information. ${ }^{75}$

\footnotetext{
${ }^{73}$ Lisa Popeil, “The Multiplicity of Belting,” Journal of Singing 64, no. 1 (October 2007): 79-80.

${ }^{74}$ Sundberg et al., "Substyles of Belting."

${ }^{75}$ LoVetri, "The Confusion About Belting," 6.
} 
The current literature has varied definitions for belt and mix, including those based on perceptual, physiological, and acoustic parameters. Of all the styles of MT singing, "legit" is the most universally agreed upon, most likely because of its similarities to classical female singing. It is defined by LoVetri as "a strong head voice such as might be produced by an opera singer,",76 and is most similar to the soprano classical voice, but with a more forward, brighter timbre. ${ }^{77}$

Defining belt, as was seen in the previous discussions on physiological, acoustic, and perceptual studies is much more challenging. In 2008, Norman Spivey compiled a review of the literature titled "Music Theater Singing...Let's Talk. Part 2: Examining the Debate on Belting." He divided the literature into two camps: those who considered belting a "pushing" or "driving up" of chest voice, almost all of which had negative connotations, and those who thought it to be a "chest dominant" "extension of the speaking voice," most of which were positive. ${ }^{78}$

Examples of current definitions in the literature include: "speech-like or yell-like in character and as the style used in much of today's music theater,"79 or "a dynamic theater sound produced from a mixed speaking voice." ${ }^{80}$ In short, belting is chest voice dominant production that acts as an extension of the speaking voice, creating a "bright,",81 "loud, brassy,",82 "high energy vocal and physical event.",83

\footnotetext{
${ }^{76}$ LoVetri et al., "Preliminary Study...," 219.

${ }^{77}$ Balog, "Guide to Evaluating MT Singing."

${ }^{78}$ Spivey, "Music Theater Singing...Let's Talk."

${ }^{79}$ Popeil, “Multiplicity of Belting," 77.

${ }^{80}$ Mary Saunders Barton, "Definitions and Thoughts on 'Belt,"” handout from "Music Theatre and the Belt Voice-II," National Association of Teachers of Singing Winter Workshop, New York, January 2001, quoted in Spivey, "Music Theater Singing...Let's Talk," 609.

${ }^{81}$ Edwin, "Belting 101, Part Two."

${ }^{82}$ Estill, "Belting and Classic Voice Quality."

${ }^{83}$ LoVetri, "The Confusion About Belting," 6.
} 
Lebowitz and Baken undertook a study "to further clarify a definition of belting in physiological and acoustic terms, ${ }^{, 84}$ specifically Schutte and Miller's definition. ${ }^{85}$ They state, It is widely accepted that belting is produced by specialized manipulation of the larynx and vocal tract. As previously stated by many others this is nearly all that can be ascertained about this controversial singing technique. Previous research on belting has provided limited and conflicting results in regard to its definition, nature, and production. $^{86}$

Mix voice continues to be more controversial in its terminology. Perhaps some of this confusion comes from those who combine terms from the MT and classical vocabulary to illustrate a tonal idea. For example, in the book So You Want to Sing Music Theater, published by the National Association of Teachers of Singing, to a novice reader, the use of undefined terms makes the definition of mix unclear:

$[\mathrm{M}]$ usic theater voices, as with classical singers, have different colors, weights, and ranges. Some music theater singers use a darker and heavier production, which employs more chest than head register (chest/mix), while others employ a lighter, more head/mix combination. Often these choices are made based on the size of the instrument. A lightervoiced music theater singer most often chooses a head/mix production, while the darker, heavier voices tend to choose the chest/mix sound. The chest/mix music theater voice

\footnotetext{
${ }^{84}$ Lebowitz and Baken, "Correlates of the Belt Voice," 159.

${ }^{85}$ Schutte and Miller, "Belting and Pop," 147.

${ }^{86}$ Lebowitz and Baken, "Correlates of the Belt Voice," 159.
} 
usually has similarities to the classical alto or mezzo voice; the head/mix voice has similarities to the classical soprano. ${ }^{87}$

A 2012 publication by Karen Kochis-Jennings et al tried to give similar labels to techniques used in music theater singing, but with scientific data to support them. They defined chest, chestmix, headmix, and head as different registers in the female voice, having distinctly separate timbres and physiological qualities. They believe that other terms frequently used by pedagogues, including belt, legit, and "mixed," are styles of singing similar to the labels by Popeil, and not registers. ${ }^{88}$

With all of these attempts at clear terminology and definitions, what pedagogic vocabulary do teachers actually use in the studio? In a 2003 survey called "Contemporary Commercial Music (CCM) Survey: Who's Teaching What in Nonclassical Music" and its 2009 follow-up, LoVetri and Edrie Means Weekly sought to collect information about those teaching CCM in the studio. They asked teachers of singing if they taught CCM styles and if so, what kind of training and performance experience they had in these styles. Weekly and LoVetri asked those teaching CCM to define the following terms: belt/belting, mix, chest/mix, and other related terms. (Legit was not included in this survey.) In both surveys the participants gave similar, though uncertain, responses. "Belt/belting” responses included "high, loud, chest-dominant, elevated larynx, long-closed glottal phase, heavy, and thyroarytenoid (TA) activity." ${ }^{\circledR 9}$ Responses for "mix" and "chest/mix" were less varied: "balance of TA and cricothyroid (CT) activity (blend of chest and head register sounds)" and Chest/mix: "chest-dominant, heavier mix, and

\footnotetext{
${ }^{87}$ Hall, So You Want to Sing Music Theater, 67.

${ }^{88}$ Kochis-Jennings et al., "Laryngeal Muscle Activity...," 182-183.

${ }^{89}$ Weekly and LoVetri, "Follow-Up CCM Survey," 372.
} 
more chest present in mix." ${ }^{90}$ Especially when defining belt and belting, respondents used a combination of perceptual and science-based terms. Respondents rarely defined mix without use of another term like chest or head.

In a similar, more recent survey, twelve expert teachers from four continents, all specialists in MT voice, "described belt as a chest or thyroarytenoid (TA) dominant sound with 'forward' 'twangy' vowels. They articulated a range of belting styles, suggesting that there may be more than one type of belt sound." 91

This survey did include "legit," which was again much easier for the pedagogues to define. They "all agreed that legit is a more classically-based vocal quality, with a brighter and 'twangier' sound than the classical voice. They suggested that for women, legit is cricothyroid (CT) or head register dominant..."92 Similar to LoVetri and Weekly's findings, most respondents “described mix as a sound that balanced chest (thick vocal folds) and head register (thin vocal folds). At the same time, teachers expressed their frustration with the term, suggesting that it lacked clarity."93

According to a recent survey of audition requirements of leading female roles in the 2014 Broadway season, the authors found that $84 \%$ of these roles required belting, over half of which is above $\mathrm{E}_{4} \cdot{ }^{94}$ They are careful to note that this does not mean these singers belt the entire show, or that the "high belt" required by producers and casting directors requires the full "chest" or M1 production found in research. The job of the casting directors is to cast what they hear as

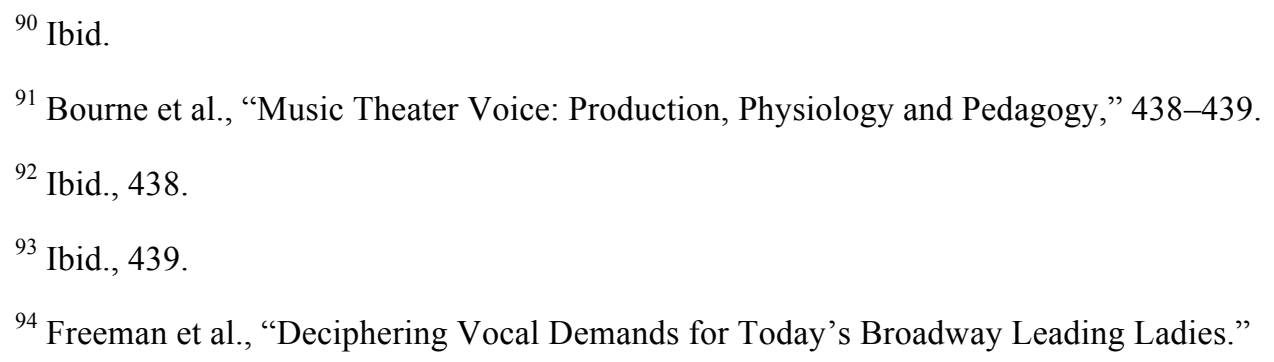


stylistically appropriate, while it is the job of pedagogues to translate this to their students using informed, objective knowledge and universal terms.

Because definitions of the terms "belt," "mix," and "legit" are under continuous debate in the voice community, a combination of the teacher's ear and the singer's perception of sound and "register" is needed to achieve the desired outcome. The following statement from the American Academy of Teachers of Singing (AATS), published in 2008, highlights the need for a distinct MT pedagogy: "Since there are significant and measurable acoustic differences between classical singing styles and popular singing styles, the Academy proposes that the techniques used to train singers in those styles should be tailored to the particular performing needs of the singer."95

${ }^{95}$ AATS, "In Support of CCM Voice Pedagogy." 


\section{Chapter 3: Method}

\section{PURPOSE}

The purpose of this study is to gather descriptions of kinesthetic feedback of professional MT singers when singing in the "belt," "mix," and "legit" styles of singing, relating their words to the visual acoustic spectrum. From this comparison, a vocabulary will be developed for pedagogues to use to relate sensation to their students.

\section{SUBJECTS}

The six subjects that participated in the study were 23-37 years of age and had a minimum of 5 years of professional MT performance experience. All subjects had performed in either a Broadway show (3 subjects) or a leading role in a national tour within the last 2 years. They were all in good vocal health with no current vocal injuries or concerns. They stated that they are comfortable producing belt, mix, and legit styles of singing. The subjects were recruited through email correspondence and through an advertisement on Facebook.

\section{MATERIALS}

Subjects' survey responses were audio recorded using the Samsung Galaxy S5 smartphone's built-in Voice Recorder software.

Sung samples were recorded using a head-mounted electret microphone at a distance of $15 \mathrm{~cm}$ on VoceVista software version 3.3. Microphone level was tested prior to recording. 


\section{PROCEDURE}

Upon entering the individual session, each subject was first asked her age and if she had any currently diagnosed voice injury or disorder. All subjects stated that they were in good vocal health. The participant then answered questions regarding recent performance experiences, inclusive of years of professional performance experience and three roles performed within the last 2 years. They were then asked how many years of training they have had in Western classical music and Contemporary Commercial Music (CCM) / Music Theatre (MT), if any. If the subject indicated they had training in CCM / MT styles they were asked two follow-up questions based on LoVetri and Weekly's $2003^{1}$ and $2009^{2}$ surveys. They were asked if any of their CCM / MT training was at a college or university (yes / no), and if their teacher(s) were trained in CCM / MT styles, or had professional CCM / MT experience (yes / no / don't know). All questions and responses were recorded using the Samsung Galaxy S5.

The final questions prior to singing addressed the subject's physical perception of "belt," "legit," and "mix" voice. "How would you perceptually describe 'belt' voice regarding sensation and production? How would you perceptually describe 'legit' voice regarding sensation and production? How would you perceptually describe 'mix' voice regarding sensation and production?" These questions serve two purposes: first, to gather descriptions of the three methods of singing discussed in this study from the point of view of the singers themselves; second, asking these questions will allow the singers a chance to think about and articulate the

\footnotetext{
${ }^{1}$ Jeannette L. LoVetri, and Edrie Means Weekly, “Contemporary Commercial Music (CCM) Survey: Who's Teaching What in Nonclassical Music," Journal of Voice 17, no. 2 (June 2003): 207-15.

${ }^{2}$ Edrie Means Weekly, and Jeannette L. LoVetri, "Follow-Up Contemporary Commercial Music (CCM) Survey: Who's Teaching What in Nonclassical Music,” Journal of Voice 23, no. 3 (2009): 367-75.
} 
differences in the three methods prior to singing vocalizations in them. As in Bourne et al., ${ }^{3}$ the investigator did not give definitions or descriptions of the methods to the singers, nor were they made aware of the exercises prior to the recording process. The investigator did, however, tell the subjects prior to singing that they would be asked a series of questions regarding their comparative kinesthetic feedback in belt, legit, and mix.

Following the interview, the subject sang an ascending C major scale four times in "legit" voice on the vowels /a/ as in "father," /æ/ as in "cat," /ع/ as in "let," and / // as in "bought" respectively. The term "legit" was purposefully not defined by the investigator in order to hear how each singer would respond to the prompt terminology. The vowels (/a/, /æ/, /ع/, /o/) were chosen in an effort to recreate the sounds found in the musical excerpts. Titze ${ }^{4}$ and Titze, Worley, and Story ${ }^{5}$ found that in "belt production" singers modify "speech-vowels" to more open, bright vowel shapes to create the desired sound. ${ }^{6}$ An E-flat major scale with the same four vowels followed. An exploratory study by McCoy asked MT students to sing ascending scales on B-flat and F in "full belt," "belt/mix," and "head voice.," C major and E-flat major were chosen for this study to more accurately reflect notes contained within the musical samples, allowing a comparison of methods used within the context of the music versus production of the same methods cued by terminology ("belt," "legit," and "mix") in singing scales. The scales

\footnotetext{
${ }^{3}$ Tracy Bourne, and Maëva Garnier, "Physiological and Acoustic Characteristics of the Female Music Theater Voice," Journal of the Acoustical Society of America 131, no. 2 (February 2012): 1586-94.

${ }^{4}$ Ingo Titze, "Formant Frequency Shifts for Classical and Theater Belt Vowel Modification," Journal of Singing 67, no. 3 (February 2011): 311-12.

${ }^{5}$ Ingo Titze, Albert S. Worley, and Brad H. Story, "Source-Vocal Tract Interaction in Female Operatic Singing and Theater Belting,” Journal Of Singing 67, no. 5 (May-June 2011): 561-572. Belting."

${ }^{6}$ Titze, Worley, and Story, "Source-Vocal Tract Interaction in Female Operatic Singing and Theater

${ }^{7}$ Scott McCoy, “A Classical Pedagogue Explores Belting,” Journal of Singing 63, no. 5 (June 2007): 546.
} 
were repeated next in "belt" voice, and lastly in "mix," again without defining the terms for the singer. All scales were recorded using VoceVista software, version 3.3.

Following the scales, each singer sang brief excerpts taken from the following three songs found in contemporary MT literature: measures 71 to 76 from “There's a Fine, Fine Line” from Avenue Q, measures 90 to 97 in "Gimme Gimme" from Thoroughly Modern Millie, and the last five measures from "The Wizard and I" from Wicked. Past research has used such samples as "Everything's Coming Up Roses"8 and "Rose's Turn" from Gypsy, "Memory" from Cats, ${ }^{10}$ "Maybe This Time"11 and "Cabaret"12 from Cabaret, "I've Got the Sun in the Morning" from Annie Get Your Gun, ${ }^{13}$ and even "Summertime" from Porgy and Bess. ${ }^{14}$ The most recent song excerpt used in a study prior to this current research was "Someone Like You" from Jekyll \& Hyde, which premiered in $1990 .^{15}$ The songs in this study were chosen as representatives of three different voice types present in MT repertoire, using MT examples since 2000 to show current trends in the industry. As LoVetri wrote,

\footnotetext{
${ }^{8}$ Johan Sundberg, Margareta Thalén, and Lisa Popeil, "Substyles of Belting: Phonatory and Resonatory Characteristics," Journal of Voice 26, no. 1 (January 2012): 44-50.

${ }^{9}$ Wendy DeLeo LeBorgne, Linda Lee, Joseph C. Stemple, and Heather Bush, "Perceptual Findings on the Broadway Belt Voice," Journal of Voice 24, no. 6 (November 2010): 678-89.

${ }^{10}$ Clayne W. Robison, Barry Bounous, and Ross Bailey, "Vocal Beauty: A study proposing its acoustical definition and relevant causes in classical baritones and female belt singers," NATS Journal 51, no. 1 (1994): 19-30.

${ }^{11}$ Amy Lebowitz, and R. J. Baken, "Correlates of the Belt Voice: A Broader Examination," Journal of Voice 25, no. 2 (March 2011): 159-65.

${ }^{12}$ Leborgne et al., "Perceptual Findings on the Broadway Belt Voice."

${ }^{13}$ Leborgne et al., "Perceptual Findings on the Broadway Belt Voice."

${ }^{14}$ Johan Sundberg, Patricia Gramming, and Jeannette L. LoVetri, "Comparisons of Pharynx, Source, Formant, and Pressure Characteristics in Operatic and Musical Theatre Singing," Journal of Voice 7, no. 4 (1993): 301-10.

${ }^{15}$ Leborgne et al., "Perceptual Findings on the Broadway Belt Voice."
} 
Just as classical singing is not "one thing," belting too is wide ranging....All of these styles may be considered as being chest register driven/dominant, with a high closed quotient, and a high decibel (sound pressure) level or intensity but they are not the same from one group to the next. Just as in classical singing we have dramatic sopranos, lyrico-spinto sopranos, and lyric-coloratura sopranos, (and many other subdivisions) so we have a wide range of belters, high and low, "warm and round," "edgy and cutting"....The instrument is unique even if the function is almost the same. ${ }^{16}$

The characters" emotional states and "type" are different in these three selections, and so the strategies the singer uses for each character may change. The subject was instructed to sing each song in character, as they would in a performance of the role. Using song excerpts allowed the investigator to hear the singer at her most comfortable, to hear what she would do naturally in a performance. The three song excerpts were emailed as .pdf files to the subjects a week prior to recording. Excerpts were recorded using VoceVista software, version 3.3.

Following the excerpts, the subject was then asked a series of questions regarding physical perception based on what they sang. "Describe what you felt or did differently in the 'belt' exercises compared to the 'legit' exercises. For example, what did you feel or do in your throat and larynx? In your head and face? In your articulators (tongue, jaw, soft palate, etc.)? If you felt no change, say so." Lastly, "When singing in the 'mix' exercises, was what you felt or did more similar to the 'belt' exercises, the 'legit' exercises, or was it unique to itself?" Responses were again recorded using the Samsung Galaxy S5.

${ }^{16}$ Jeannette L. LoVetri, “The Confusion About Belting: A Personal Observation," NYSTA Voice Prints 10 (September-October 2012): 6. 


\section{ANALYSIS}

VoceVista recordings were analyzed using formant estimations based on spectral peaks and known vowel formant locations. ${ }^{17}$ Given average formant frequencies for women, formant/harmonic interactions were estimated based on spectral peaks specifically, in the scales, looking for changes in resonance strategies. Next, specific sustained pitches in the song samples were compared to the resonance strategies used in the scales. The scales were analyzed specifically observing any changes in resonance strategy at different pitches in "legit," "belt," and mix.

Lastly, singers' verbalizations of their definitions of "belt," "mix," and "legit" and what they felt or did to sing in those styles were compared to the resonance strategies analyzed on VoceVista. These comparisons were used to develop a vocabulary useful for pedagogues.

${ }^{17}$ Scott McCoy, Your Voice: An Inside View, $2^{\text {nd }}$ ed., (Delaware, OH: Inside View Press, 2012). 


\section{Chapter 4: Results}

\section{INTRODUCTION}

Training and experience of the subjects is followed by their stated definitions and descriptions of the sensations of belt, legit, and mix as drawn from the survey responses. Analysis of the acoustic qualities of the sung examples begins with $\mathrm{C}$ major scales in belt, legit, and mix followed by reporting of the E-flat major scales. Further summary of the interviews continue, highlighting the importance of context and character when singing MT repertoire, a common theme in the singers' answers. Lastly, exclusions are described. For more detail, full transcripts of the interview portions are provided in Appendix 4. Identifying information has been redacted from the survey responses to protect subject anonymity.

\section{SUBJECTS}

The six subjects participating in the study were between the ages of 23 and 37 years, with a minimum of five years of professional performance experience. All subjects had performed in either a Broadway show or a leading role in a national tour within the last two years (Table 1). None of the subjects had known voice injuries or disorders at the time the study was conducted.

All subjects but S1 had somewhat balanced training in Western classical and CCM styles (Table 2). However, all subjects had most recently studied with CCM specific teachers, either in their college or university or privately in New York City. Of the teachers mentioned in interviews, all but two had specific training to teach CCM styles. One of these two teachers had 
professional MT performance experience. In total, 4 of the subjects' $6 \mathrm{CCM}$ teachers had performance experience in MT or CCM. According to the subjects, 4 of these teachers specialized in MT, and 2 considered themselves to be pop/rock specialists. Four of the 6 were trained to teach MT and 4 of 6 had performance experience. Only 1 of the 6 teachers had neither performance experience nor specific training to teach MT or CCM styles. Although these numbers are greater than the percentages found by Weekly and LoVetri, ${ }^{1}$ the subjects from this study all received degrees in MT performance from established MT programs, 5 as undergraduates and one as a masters student. ${ }^{2}$

Table 1. Subject age and experience

\begin{tabular}{|c|c|c|c|}
\hline & Age & $\begin{array}{c}\text { Yrs. } \\
\text { Professional } \\
\text { Experience }\end{array}$ & Most Recent Role \\
\hline $\mathbf{s} 1$ & 33 & 14 & Broadway (lead) \\
\hline S2 & 25 & 7 & tour (lead) \\
\hline S3 & 37 & 19 & Pre-Broadway (supp.) \\
\hline S4 & 27 & 6 & tour (lead) \\
\hline S5 & 25 & 7 & tour (lead) \\
\hline s6 & 23 & 5 & Broadway (ens.) \\
\hline
\end{tabular}

${ }^{1}$ Edrie Means Weekly and Jeannette L. LoVetri, "Follow-Up Contemporary Commercial Music (CCM) Survey: Who's Teaching What in Nonclassical Music," Journal of Voice 23, no. 3 (2009): 367-75.

${ }^{2}$ This information was a part of the interviews conducted with the subjects, however it will not be found in the transcripts. The information is summarized without identifying characteristics to ensure confidentiality of both the subjects and their teachers, past and present. 
Table 2. Years of training

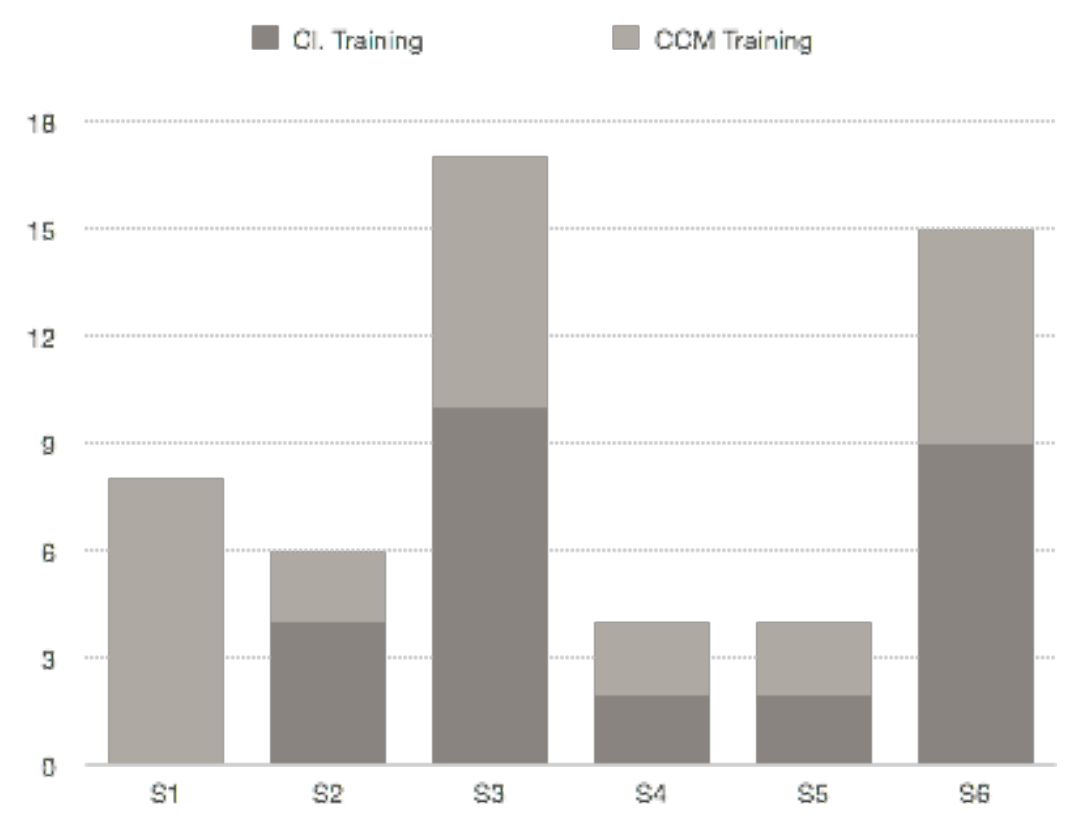

\section{DEFINITIONS}

There were two interview sections, one prior to and one following the sung exercises. The subjects were able to articulate the differences between the three terms (belt, mix, and legit) in the study without hesitation, and were aware of tonal and kinesthetic differences even when slight. In most cases, singers felt more confident in their descriptions after singing the exercises, and often clarified or went into more detail in the second interview portion.

The six subjects defined each of the three terms in a similar manner. Subjects defined "belt" as "forward," "ping-y," and "in the mask." Only two subjects described it as "chest voice": subjects S6, whose training was mostly Western classical and "musical theater legit," and S3, whose training until graduate school was strictly Western classical. It was this definition that kept S6 from attempting the E-flat belt exercises. Her association with belt as a higher than normal chest voice production, a popular definition among Western classical teachers, made her 
believe she was unable to produce the desired sound. Three subjects specifically mentioned a "dropped," "flat" tongue (S5: a "relaxed sensation" at the back of her tongue) in both their belt and mix.

The sensation of legit was defined as "dome-y," "bigger" and "more open" than belt, specifically with a more "open palate." Three of the subjects stated that it was a high and up sensation, as opposed to the high and forward sensation of belt. As with "chest voice" for belt, only S6 and S3 used the term "head voice" in defining legit.

Mix was also defined similarly among the singers surveyed, and they often referred back to belt and legit in their definitions. For example, "belt is like a mix placement," but with a "bigger sound." When asked if her mix is more similar to belt or legit, S1 said, "I don't differentiate too much" in their production, though she recognizes that the sounds are certainly different. This goes along with statements from some teachers who teach belt/mix, and don't separate the two.

Half of the subjects stated that mix was a unique sensation, with one adding that it depends on the register: she feels it personally as closer to belt, but it has more of a legit sensation towards the E-flat in the scales. Of the two respondents who did not feel mix as a unique sensation, S1 (who had the most MT training) said her mix was closer to her belt; S6 (who had the most Western classical training) felt it closer to legit. S6 stated that there was a "mix-belt" but she didn't do it, hers was strictly "legit-mix." 


\section{ACOUSTIC ANALYSIS}

Five of the subjects each sang a total of 24 scales: a C major scale and an E-flat major

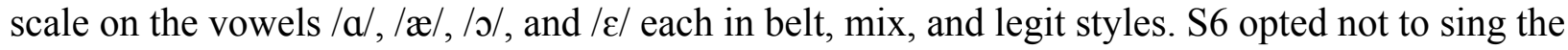
E-flat belt scales. All 6 subjects sang 3 song excerpts, "The Wizard and I," "Gimme Gimme," and "There's a Fine, Fine Line.” In general, the E-flat scales displayed clearer formant tuning strategies. From a pedagogic perspective, these singers might have needed to execute the E-flat scale more efficiently in order to make this elite vocal maneuver. For example, S5 sounded yelllike for the first few $\mathrm{C}$ belt exercises, but had no trouble with the E-flat scales.

Present in all belt scales were consistently strong harmonics above $4 \mathrm{kHz}$, beginning at pitches between $\mathrm{F}_{4}-\mathrm{A}_{4}$ (fig. 1). This area, past the traditional female primo passaggio, is where LoVetri defines belt as beginning. ${ }^{3}$ Though the amplitude varied from singer to singer, these high harmonics in each subject were greater in belt than mix, and greater in mix than legit. The strength of these higher harmonics corresponded with the singer's association of "mix." For example, S6, who felt mix as similar to legit, had weaker mix harmonics, while S5, who associated mix more with belt, had stronger mix high harmonics. This supports McCoy's suggestions that "in belt, strong harmonics are found through $10 \mathrm{kHz}$; in head voice, harmonics above $4 \mathrm{kHz}$ are relatively weak." $\mathrm{He}$ also notes, "the acoustic spectrum of belting is broader with formant regions that are less clearly defined." Although in some cases formants were either close together or straddling a single harmonic, thus influencing those harmonics around the

\footnotetext{
${ }^{3}$ Jeannette L. LoVetri, “The Confusion About Belting: A Personal Observation," NYSTA Voice Prints 10 (Sept.-Oct. 2012): 4-7.

${ }^{4}$ Scott McCoy, “A Classical Pedagogue Explores Belting,” Journal of Singing 63, no. 5 (June 2007): 545549.

${ }^{5}$ Ibid.
} 
formant as well, the results of this study did not agree entirely with McCoy's statement. The formant zones were often quite clearly defined, especially, as mentioned above, in the higher pitches of the E-flat scales.

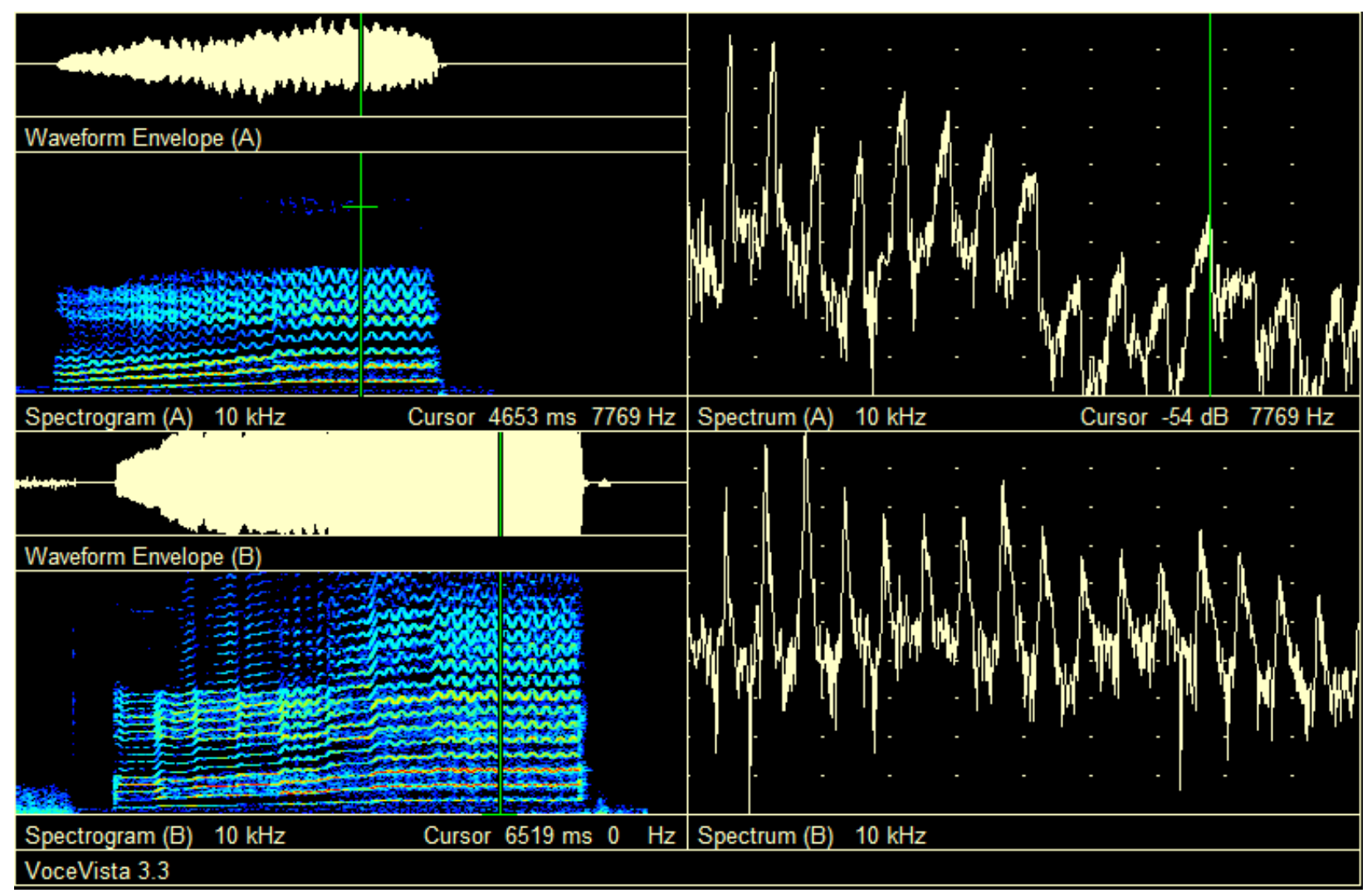

Figure 1. S3 E-flat scales in legit (Above) and belt (Below)

The $\mathrm{C}$ belt scales matched findings in the literature, ${ }^{6}$ showing a variety of acoustic tuning strategies from subject to subject. Between /a/,/っ/, and /æ/, however, each subject showed consistent tuning strategies. All but S2 used a pivot note to change tuning strategies between F4

${ }^{6}$ Tracy Bourne and Maëva Garnier, "Physiological and Acoustic Characteristics of the Female Music Theater Voice," Journal of the Acoustical Society of America 131, no. 2 (February 2012): 1586-94. 
and B4 to an $\mathrm{H}_{2} / \mathrm{F}_{1}$ dominant sound. This supports Miller's research. ${ }^{7}$ The two singers who had a "shout" or "yell" like sound in this scale, S4 and S6, both struggled to release the earlier tuning of either $\mathrm{H} 3 / \mathrm{F}_{2}$ or $\mathrm{H} 4 / \mathrm{F}_{2}$ (fig. 2). The success of this release greatly influenced timbre. S2 kept an $\mathrm{H} 3$ dominant spectrum throughout the scale, switching on either $\mathrm{A}_{4}$ or $\mathrm{B}_{4}$ (depending on vowel) from $\mathrm{H} 3 / \mathrm{F}_{1}$ to $\mathrm{H} 3 / \mathrm{F}_{2}$ (fig. 3). The transition was aurally smooth.

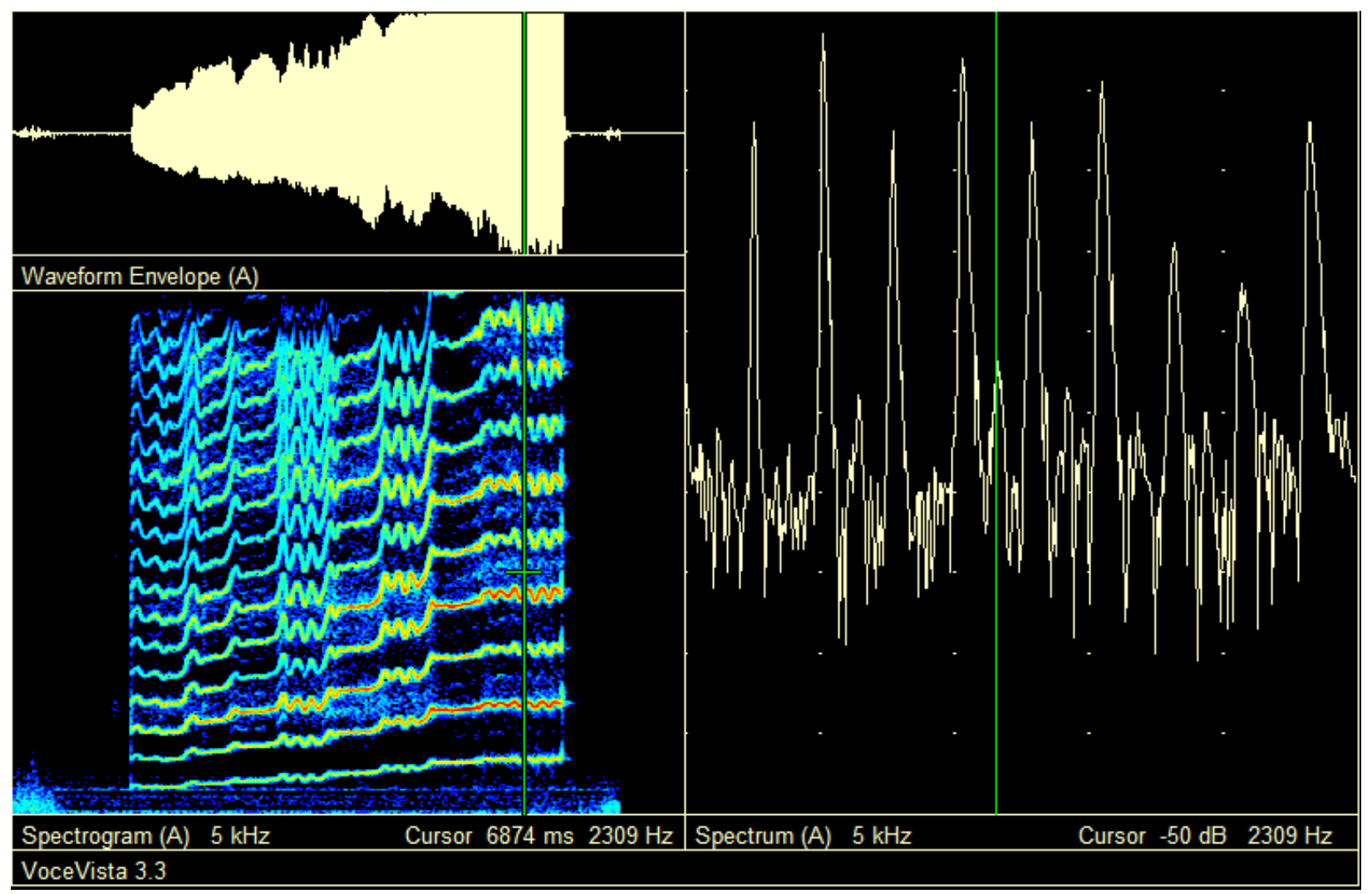

Figure 2. $\mathrm{S} 4 \mathrm{C}_{5}$ belt on /æ/, showing lack of release of $\mathrm{H} 4$ with a high $\mathrm{F}_{2}$

${ }^{7}$ Donald G. Miller, Resonance in Singing: Voice Building through Acoustic Feedback, (Princeton, NJ: Inside View Press, 2008), 94-95. 




Figure 3. S2 $\mathrm{C}$ belt scale on /a/, showing lowered $\mathrm{F}_{1}$ from $\mathrm{B}_{4}$ Above to $\mathrm{C}_{5}$ Below

The $\mathrm{C}$ legit scales were consistently produced as well from singer to singer, but more consistent within each subject's examples. The subjects showed either similar amplitudes of H1 and $\mathrm{H} 2$ on $\mathrm{B}_{4}$ and $\mathrm{C}_{5}$, similar to that used in the highest pitches of the E-flat scale, or stayed in a $\mathrm{H} 2 / \mathrm{F}_{1}$ dominant tuning (fig. 4). There were clear pivot notes in all 6 singers. 


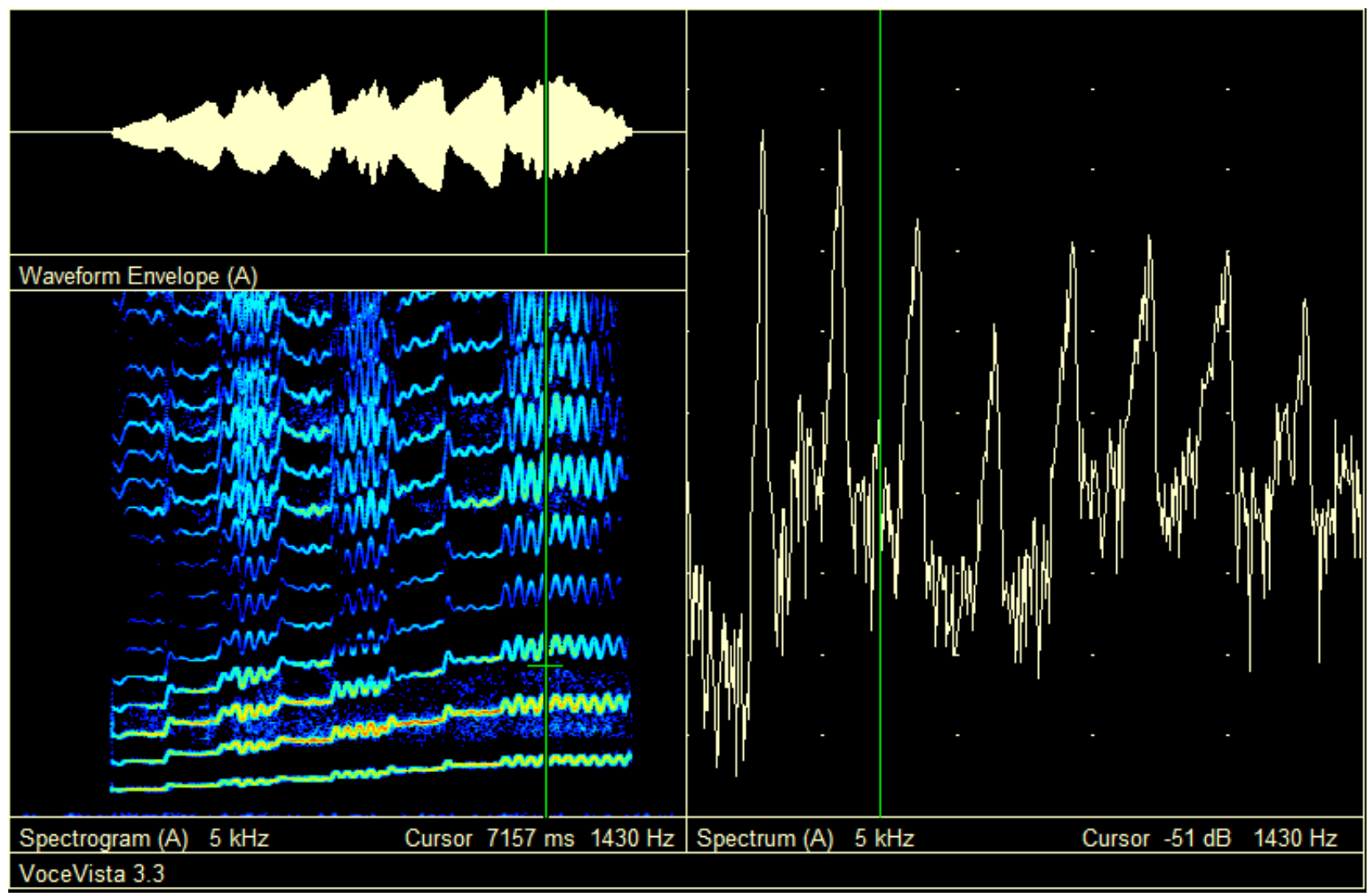

Figure 4. S1 C legit scale on /o/

The $\mathrm{C}$ scale in mix voice displayed the least consistency. This is perhaps because it was the first scale they were asked to perform in mix, or perhaps because the range of $\mathrm{C}_{4}$ to $\mathrm{C}_{5}$ gave them more strategies from which to choose. S5 noted that it was difficult to mix in a low range, that it ended up being closer to her belt. Results are not conclusive due to this variety within each singer's examples and from singer to singer. They did maintain a level of higher harmonics between that of belt and legit, as well as tuning strategies that were different from belt and legit. Often in mix exercises when $\mathrm{H} 2 / \mathrm{F}_{1}$ tuning was employed, the level of $\mathrm{H} 1$ and $\mathrm{H} 3$ depended on the singer's perception of mix as closer to legit or belt voice. Belt had a stronger H3 influenced by a higher $\mathrm{F}_{2}$, legit a stronger $\mathrm{H} 1$ influenced by a lower $\mathrm{F}_{1}$ (fig. 5). 


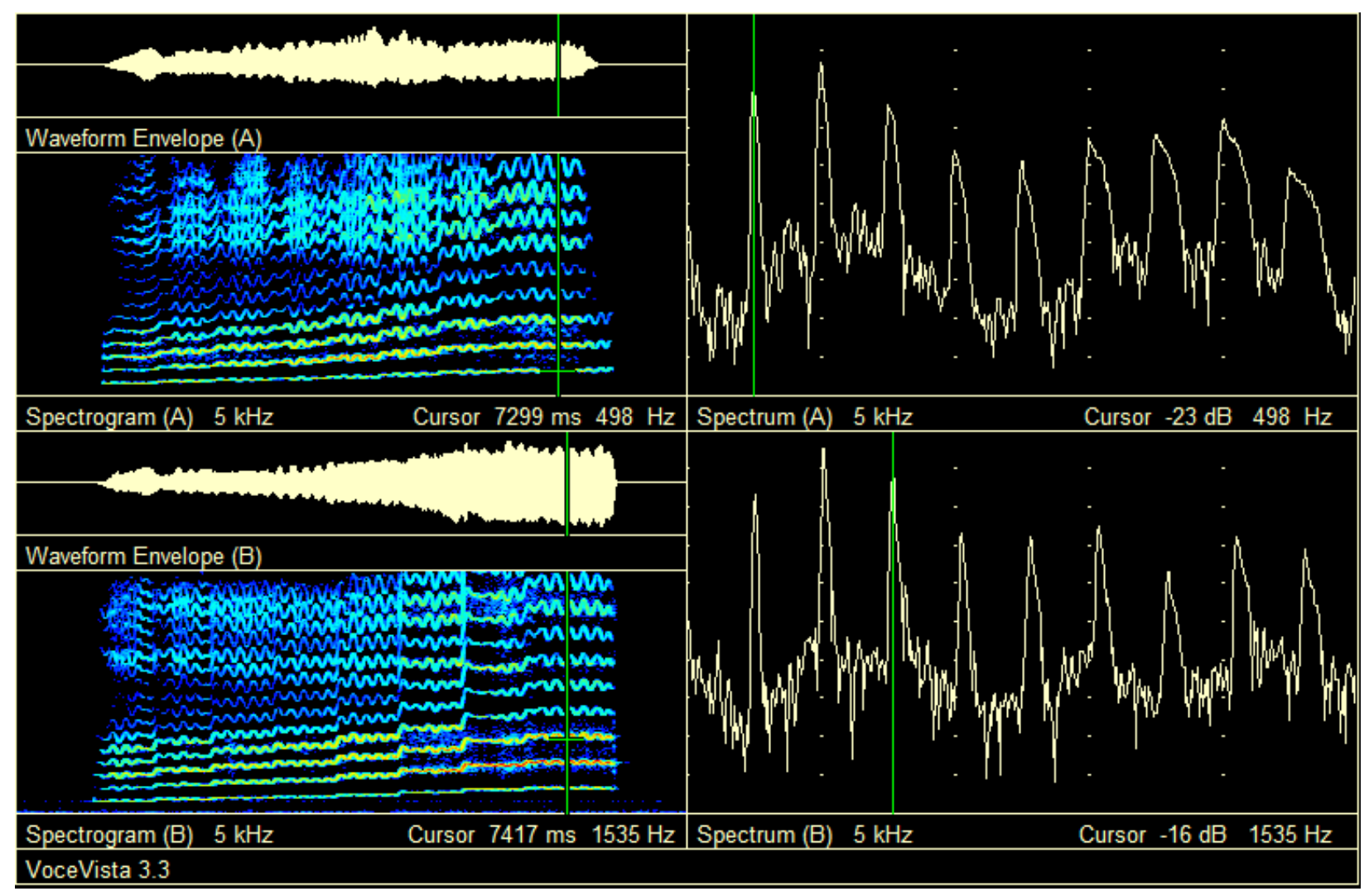

Figure 5. Above: S6 C mix scale on /o/, higher $\mathrm{H} 1$ than $\mathrm{H} 3$

Below: S5 C mix scale on /o/, higher H3 than $\mathrm{H} 1$

Five of the 6 singers sang the E-flat belt scale. S6, who associated belt with pure chest voice, declined to sing this exercise. Divergently from the $\mathrm{C}$ scales, there was great consistency within each singer's E-flat belt scale. Only S4, who found difficulty singing the exercise on the /æ/ vowel, showed differences between the three vowels on the E-flat belt scale. S3 used an H3/ $\mathrm{F}_{2}$ dominant tuning while four others used an $\mathrm{H} 2 / \mathrm{F}_{1}$ dominant tuning (S1, S2, S4, and S5) (fig. 6). Singers $\mathrm{S} 4$ and $\mathrm{S} 5$ had a noticeable peak as well of $\mathrm{H} 3$, due to a reaction to the second formant. Each singer used an identical strategy for $/ a /, / æ /$, and $/ \mathrm{\jmath} /$ for each $E b_{5}$ in belt voice (fig. 7-9) with the exception of S4's /æ/ vowel, which was unstable and varied with vibrato. 


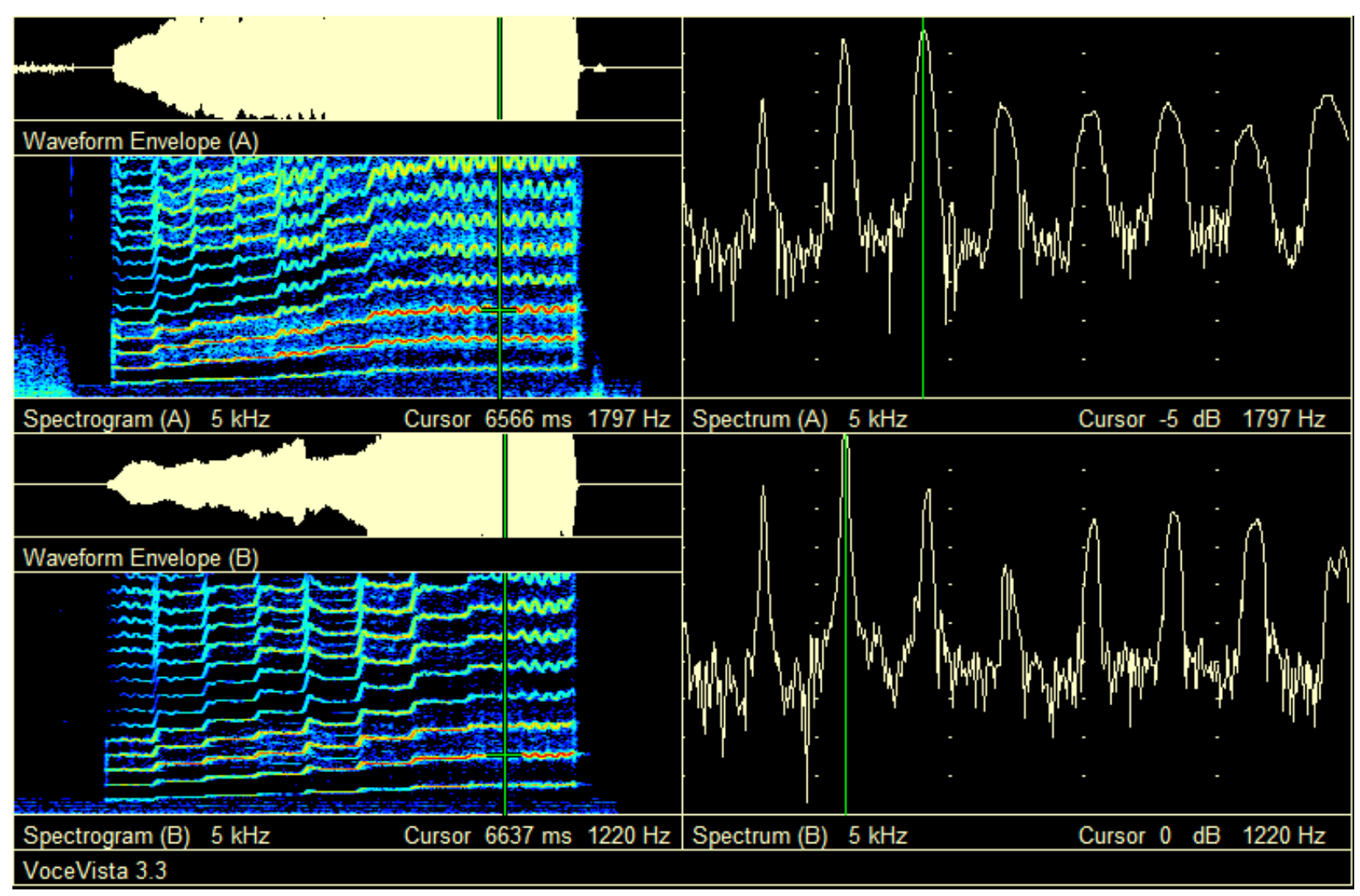

Figure 6. Above: S3 E $b_{5}$ belt on /a/; Below: S2 E $b_{5}$ belt on /a/
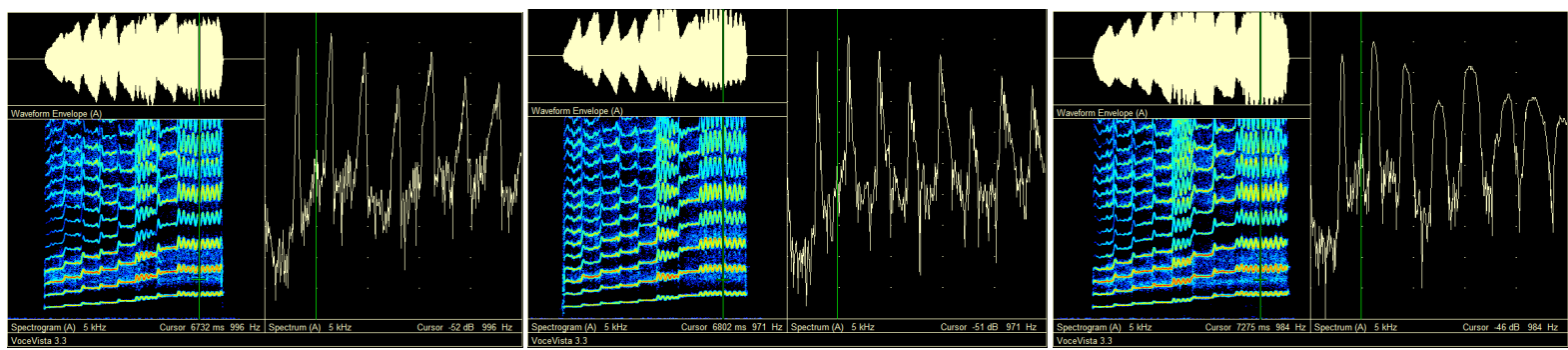

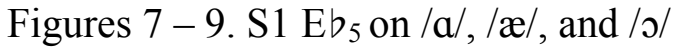

Though the final acoustic strategies at the top of the E-flat belt scale (between $\mathrm{C}_{5}$ and

$\mathrm{E} b_{5}$, depending on the singer) were similar from subject to subject, there was more variety in transitions below these pitches. Some singers used an earlier pivot point in addition to the one described above to navigate the range from $E b_{4}-E b_{5}$. This first transition was similar to that in 
the $\mathrm{C}$ major scale, and occurred between $\mathrm{F}_{4}$ and $\mathrm{C}_{5}$. All 5 E-flat belt scales on /a/, /æ/, and /a/ (with the exception of S5's /a/) either maintained $\mathrm{F}_{1}$ (stopping its tracking) or lowered $\mathrm{F}_{1}$ on the pivot note (fig. 10). The aural result was a more "close" timbre as the second harmonic passed through the first formant. The next note "opened." ${ }^{\prime 8}$ This is similar to the method used in the C scales in the area of $\mathrm{F}_{4}-\mathrm{B}_{4}$.

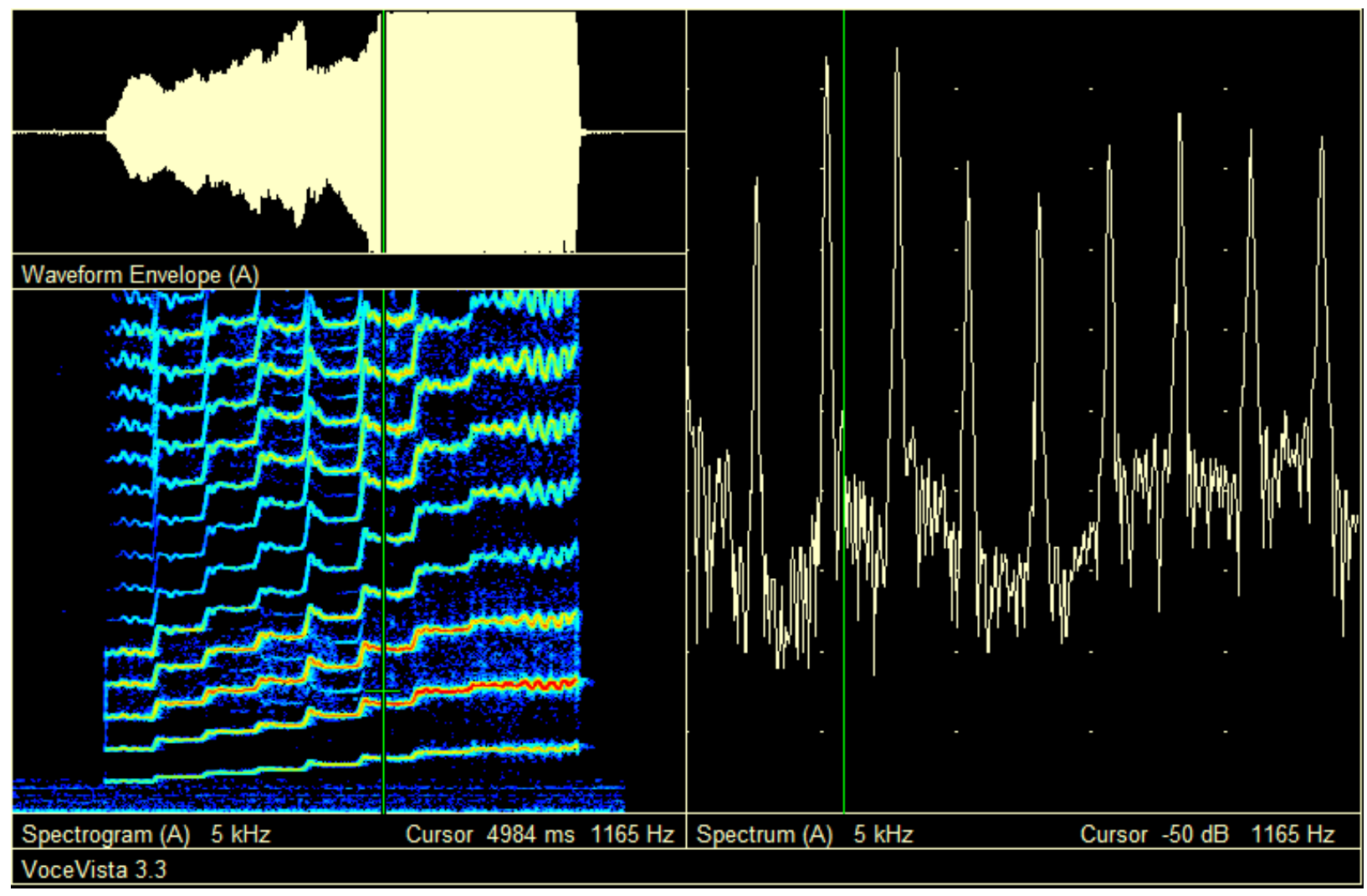

Figure 10. S2 E-flat belt scale on /a/, showing pivot note on $\mathrm{C}_{5}$

The E-flat scales were consistent throughout the subjects in legit voice. Beginning at either $\mathrm{D}_{5}$ or $\mathrm{E} b_{5}$, depending on singer and vowel, subjects lowered $\mathrm{F}_{1}$ while maintaining a raised $\mathrm{F}_{2}$ to create a double tuning that was nearly equal in all voices (fig. 11). With an $\mathrm{F}_{1}$ between $\mathrm{H} 1$

${ }^{8}$ Kenneth W. Bozeman, Practical Vocal Acoustics: Pedagogic Applications for Teachers and Singers (Hillsdale, NY: Pendragon Press, 2013). 
and $\mathrm{H} 2$ and $\mathrm{F}_{2}$ between $\mathrm{H} 2$ and $\mathrm{H} 3$, a balanced $\mathrm{H} 1 / \mathrm{F}_{1}$ and $\mathrm{H}_{2} / \mathrm{F}_{2}$ tuning occurs. This tuning was consistent among all six singers, though 5 of the 6 leaned slightly more towards either $\mathrm{H} 1 / \mathrm{F}_{1}$ dominant or $\mathrm{H} 2 / \mathrm{F}_{1}$ on one of the three vowels, in all but one case on the /æ/ vowel. This phenomenon has not been described in the current literature, and shows a distinct difference between MT legit and Western classical female singing.

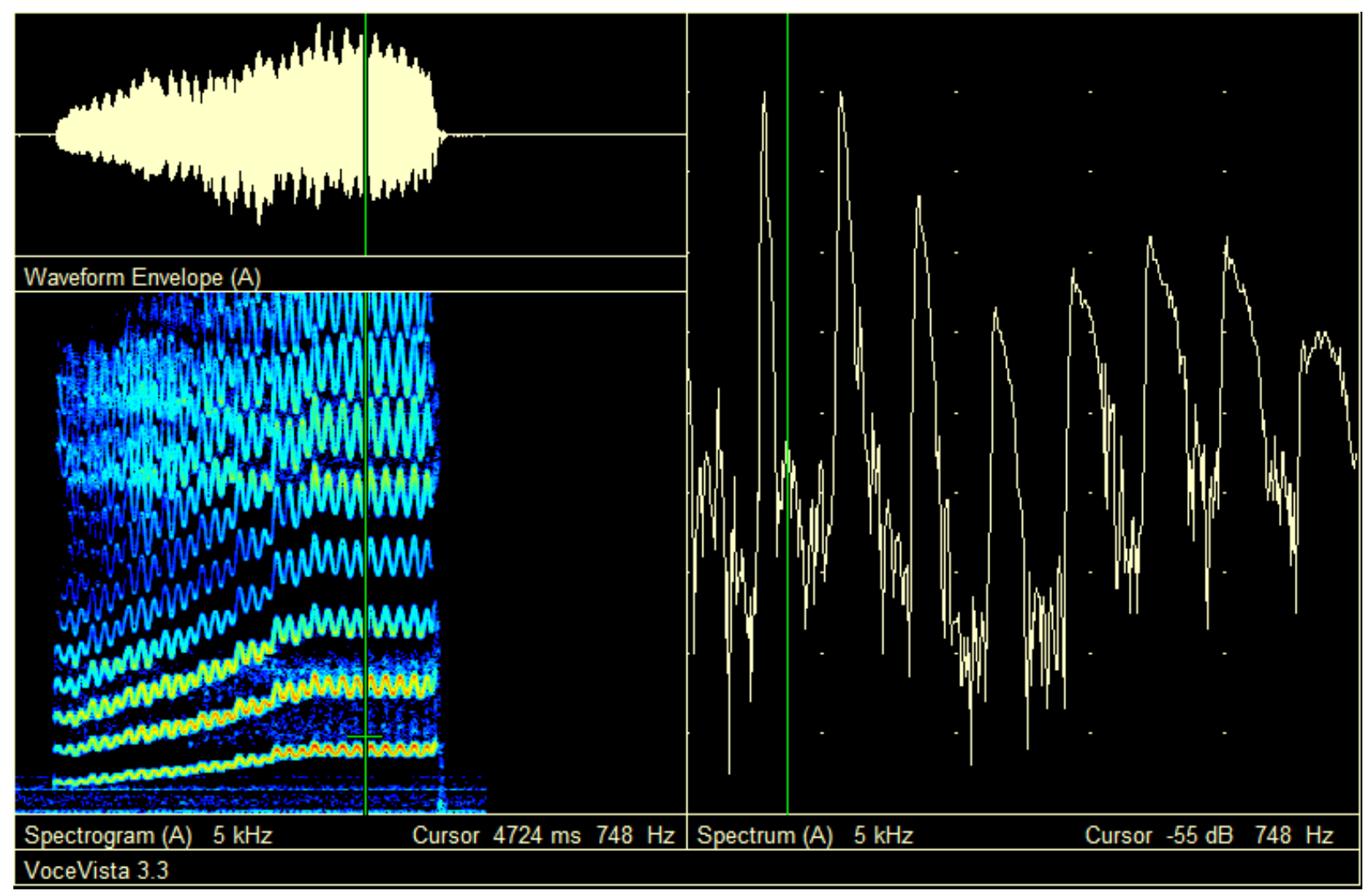

Figure 11. S3 E-flat legit scale on /a/

Mix scales on E-flat varied between subjects, but were consistent within each subject's samples. Singer S6 maintained a similar strategy as her legit scales (/a/ had slightly more dominance in $\mathrm{H}_{2} / \mathrm{F}_{2}$ ), but with the greater appearance of high harmonics as described earlier. All 6 subjects used the same strategy on their individual /a/ and /o/ vowels, only S4 (who had much 
difficulty with the E-flat/æ/ vowel in all styles) and S1 showed changes on the /æa/ vowel in mix. S1's was the same as her legit/a/vowel, but again with more high harmonics present.

\section{INFLUENCE OF CONTEXT AND CHARACTER}

Four subjects mentioned the difficulty of singing with only the prompts of "belt," "mix," and "legit," because of the lack of context or character. Singers S4 and S3 both had a noticeable break in their voices in at the first of their mix scales while trying to determine "which mix" they were to use. S3 agreed that the variety of sounds they are required to make in shows and auditions doesn't necessary align with only three terms: “I'm just all, sort of fascinated to sort of sit down and think about things more deeply. I just sort of sing and the voice goes where it goes, so it's been a long time since I sort of thought about compartmentalizing the sounds, and words." This supports LoVetri's statement that the demands on the MT singer change with the character demands within a show or even a single song. ${ }^{9}$

Though the sustained pitches in the excerpts were on similar vowels and pitches as studied in the scales, tuning strategies and vowel choices varied both from subject to subject and even within the same sample. Following the exercises, S1 noted: "the second you put down something like 'The Wizard and I' there's a placement that's different from anything that I did in the exercises." She continues, "I'm assuming it has to do with words, context, previous knowledge of the song...but you know, you get handed this and you know what they [casting directors] want to hear." Specific tuning strategies within the excerpts were thus inconclusive.

\footnotetext{
${ }^{9}$ Jeannette L. LoVetri, "Contemporary Commercial Music: More than One Way to Use the Vocal Tract," Journal of Singing 58 (January 2002): 251.
} 
There were several consistent findings across the vowels and pitch ranges. First, vibrato was far more present and consistent in the legit exercises than in belt and mix. The use of vibrato changed both from subject to subject and within each subject's examples. In the interview, S1 described why, saying it's different depending on character choice, giving a comparison between the belting in "I Cain't Say Know" from Oklahoma! and "The Wizard and I" excerpt. Both she and S3 commented on the current trend of straight-tone belt in shows.

Four of the six singers specifically mentioned the importance of repetition and consistent practice when singing in belt, mix, and legit. For example, S3 hadn't been "called on" to mix lately, only belt, so her mix was harder to access. S6 just sang a "very legit" show and found it harder to access her belt. She said, "like a dancer," the muscles needed to stay active.

\section{EXCLUSIONS}

The $/ \varepsilon /$ exercises were also excluded from analysis, as the results varied greatly both within a single subject and across subjects. When asked to sing a scale on $/ \varepsilon /$, the singers either struggled with the exercise as they attempted to maintain as pure a vowel as possible, or modified quickly towards /æ/. For these reasons, the findings focused on changes and similarities between $/ \mathrm{a} /$, /æ/, and /o/. 


\section{Chapter 5: Discussion}

\section{ADVOCATING FOR MT SPECIFIC PEDAGOGY}

The results of this study support the need for stylistically specific music theater pedagogy as suggested by AATS. ${ }^{1}$ Information provided by the six professional participants, both through interview and sung exercises, shows a clear difference between techniques they successfully use in the MT industry and those taught to classical singers. The foundations of good singing still remain: efficiency of respiration, lack of unnecessary muscle tension, stylistically appropriate resonance, and laryngeal stability, however the manner in which those aspects are employed is different enough between styles that a separate pedagogy is necessary. Western classical and MT singing are different kinesthetically, acoustically, and stylistically. The approaches in the studio should match those differences.

The subjects' claim of difficulty when switching between MT styles without consistent practice is an argument in favor of MT pedagogy. This suggests that the teaching of Western classical techniques to these singers could be a hindrance in developing voices. If working singers struggle to quickly switch from the demands of belt to those of mix, they would have greater difficulty moving from classical techniques to belt or mix. Even legit singing, which has previously been described as similar to female Western classical singing but "brighter,"2 showed

\footnotetext{
${ }^{1}$ American Academy of Teachers of Singing, "In Support of Contemporary Commercial (nonclassical) Voice Pedagogy," 2008.

2 Julie E. Balog, “A Guide to Evaluating Music Theater Singing for the Classical Teacher," Journal of Singing 61, no. 4 (April 2005): 401-6.
} 
a different acoustic tuning strategy, and therefore a different vocal tract shape from what has been previously observed in Western classical singers. ${ }^{3}$

Many Western classical pedagogues advocate a tall, open, vertical space for singing. The most similar shapes in MT and classical singing, as described in the literature, are those associated with legit. The descriptions of "dome-y," like "an egg" in the mouth, high, "open palate," are, in fact, similar to descriptions used in classical pedagogy. Despite this similarity in sensation, a distinct difference in the acoustic spectrum exists between MT legit and Western classical technique; the singers in this study demonstrated a balance of $\mathrm{H} 1$ and $\mathrm{H} 2$ in legit scales that does not match classical singing's $\mathrm{H} 1$ dominance (fig. 10, pg. 56).

The subjects in this survey described a divergent sensation when singing in belt and mix styles. S4 described her belt as "moving horizontally out as opposed to vertically out," and S6 said her mouth shape "flattened" in belt, and shaped her hands parallel to each other in a horizontal position to show her sense of the sound. S5 had a similar sense in belt and mix of a "nice, flat tongue." The horizontal, flat shape described for these styles supports research on the mouth and vocal tract shape of MT singers. ${ }^{4}$

There is little debate about the acoustic differences between female singers in the Western classical tradition and female belt and mix singers. Though no completely consistent acoustic patterns in belt and mix were found either in the literature or in this study, the choices made by MT singers in belt and mix do not line up with the H1/F1 "whoop" timbre used in classical head voice. ${ }^{5}$

\footnotetext{
${ }^{3}$ Kenneth W. Bozeman, Practical Vocal Acoustics: Pedagogic Applications for Teachers and Singers (Hillsdale, NY: Pendragon Press, 2013), 32-36.

${ }^{4}$ Ingo Titze, Albert S. Worley, and Brad H. Story, "Source-Vocal Tract Interaction in Female Operatic Singing and Theater Belting,” Journal Of Singing 67, no. 5 (May-June 2011): 561-572.

${ }^{5}$ Bozeman, Practical Vocal Acoustics.
} 
When building an MT voice, many colors, ranges, and techniques must be accessible to singers at all times. The singers recorded and interviewed for this study were generally able to quickly shift style by name (with only the prompt of terminology: belt, legit, and mix), and by character, in the three song excerpts. They understood that to properly sing the songs given to them from Wicked, Thoroughly Modern Millie, and Avenue Q, they must understand the character type they were to portray, that character's vocal style and demands, as well as the circumstances found in the script. These professional singers knew which of the characters they would be hired to play, and which they would not be hired to play because of an awareness of what was expected of their singing, type, and other skills such as dance. The same singer that would play Elphaba in Wicked would most likely not be cast as Kate Monster in Avenue Q, nor Millie in Thoroughly Modern Millie. Because of this, choosing appropriate repertoire is equally as important in allowing students to explore the variety of sounds of which they are capable.

It was encouraging that only two of the six singers associated "belt" and "legit" with "chest voice" and "head voice," respectively. With the term belt being associated as pushing the chest voice too high in the Western classical pedagogical community, this is an important distinction to note. As encouraged by many prominent teachers of MT and CCM styles, female CCM singers need to have access to and control over all mechanisms of their voice. CCM training is not "chest voice" training. Isolating and strengthening, then blending to a seamless whole allows singers to no longer think about the specific labels and let the character speak, as verbalized by several of the singers in their interviews. At this stage in her career, S3 said that "compartmentalizing" the individual styles was a challenge, since in normal performance situations she sings "and the voice goes where it goes." 
Listening and knowledge of repertoire is essential for MT singers, to know what is expected but unsaid. This is learned both on-the-job and in auditions, as with the two subjects who discussed vibrato trends in the current industry. S1 stated that, though vibrato would be appropriate when belting a song like "I Cain’t Say No" from Oklahoma!, if auditioning for Wicked she would anticipate the casting directors to want "straight-tone, straight-tone, straighttone." MT students need to be prepared to make quick changes, like straight-tone singing, when auditioning for shows.

There are many teachers that have already established CCM and MT pedagogies, including Jo Estill, Jeannette LoVetri, Elisabeth Howard, and Lisa Popeil, among others. Many programs also exist for teachers who are interested in learning this style, both as degree granting programs of study and summer workshops. NATS offers CCM and MT specific topics often in their regional and national conferences, as well as in the popular online "NATS Chats" offered on their website.

\section{PEDAGOGIC APPLICATIONS}

In the MT studio, teachers need to feel comfortable breaking free of traditional bel canto exercises. For those teachers wanting to teach these styles without having produced the sounds themselves, the singers in this survey provided some applicable vocabulary. To describe belt and mix, the words "up and around," "forward," and "ping-y" were used. S5 described belt as a "relaxed sensation" in her throat, paired with a lot of buzzing "in the mask." The singers agreed that they sensed resonance or "placement" in their nasal cavities, however only one singer called 
the sound "nasal," again S6 with the least belt and mix training. For students struggling with finding their MT sound, nasal sounds can be used, but only as one method. ${ }^{6}$

Understanding the student's vocal history is important in communicating MT sensations. The most natural sounds for the subjects tended to be the ones they learned first: S5 felt more "tension" during legit exercises, where S3 felt more "awareness of," and "pressure" in her neck in the belt exercises.

Four singers stated that mix is "the easiest," or "the most effortless" sound for them to make, as it is closest to how they talk. Belting as well was described as "like singing on your speaking voice, with more support." Because of this relationship to speech, using words and phrases in vocalizes instead of traditional vowel and consonant combinations would be helpful. In vocalises without words or lines of text, students should be encouraged to make more "speech-like" vowels, as they tend to create a more natural, horizontal, "flat" mouth shape as described by the singers in this study.

The vowels needed to train female MT singers can differ from those often used in the Western classical studio. Where students are often taught to round and heighten vowel shapes to maintain an $\mathrm{H} 1 / \mathrm{F}_{1}$ "whoop" timbre towards the top of the staff, in MT the goal is to maintain more speech-like sounds, choosing high $F_{1}$ vowels like /a/ and /æ/ and maintaining a more horizontal shape. In determining specific vowels for vocalizing, the consistency of the pivot note in the belt scales can be of great use.

Similar to male Western classical singing, using a rounder vowel at important pivot areas in the belt/mix voice (F4-B4 and D5-E5) allows MT singers to lower $\mathrm{F}_{1}$ frequencies to more easily establish a new acoustic coupling. For example, in S2's E-flat belt scale on the vowel/a/,

${ }^{6}$ Jeannette L. LoVetri, “The Confusion About Belting: A Personal Observation,” NYSTA Voice Prints 10 (Sept.-Oct. 2012): 4-7. 
at the pivot pitch of $\mathrm{C}_{5}$ she achieved equal amplitudes of $\mathrm{H} 2$ and $\mathrm{H} 3$. After achieving this

balance, she changed to more of an / $/$ / vowel, which lowered $\mathrm{F}_{1}$ back to a $\mathrm{H} 2 / \mathrm{F}_{1}$ tuning that could be taken higher (fig.12). This acoustic strategy could be useful for young belters who struggle with a high larynx to make the transition through the $\mathrm{B}_{4} / \mathrm{D}_{5}$ range, and possibly higher.

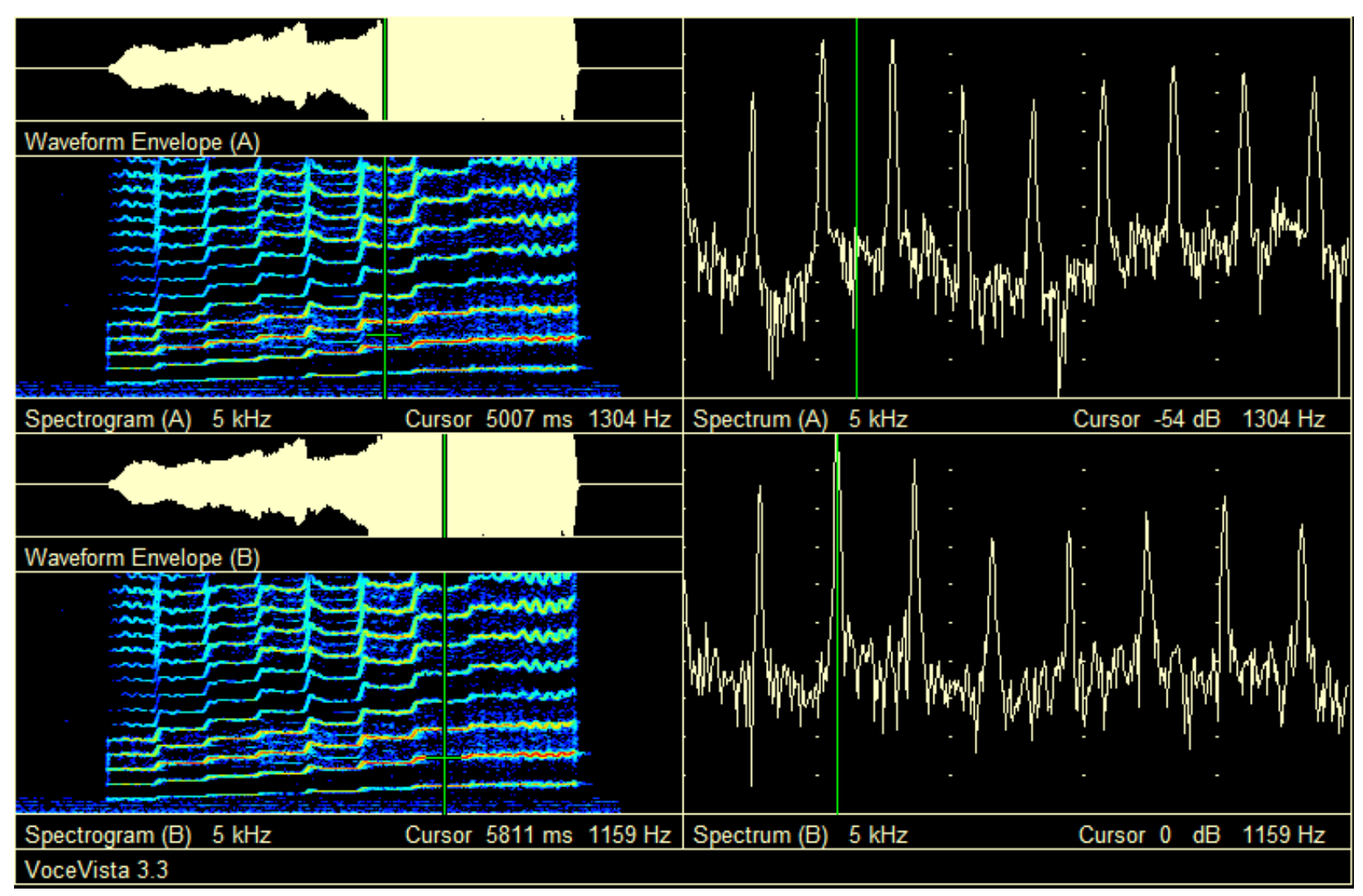

Figure 12. S2 E-flat belt scale on /a/

Above: Pivot note on $\mathrm{C}_{5}$

Below: Lowered $\mathrm{F}_{1}$ for new tuning on $\mathrm{D}_{5}$

In training MT legit, a stable laryngeal position is necessary, as in classical singing. In the scales, however, the singers in this study showed a consistent $\mathrm{H} 2 / \mathrm{F}_{2}$ tuning as well as the $\mathrm{H} 1 / \mathrm{F}_{1}$ "whoop" timbre desired by classical female singers. To achieve this added tonal color (the "brightness" referred to in the literature) in legit, singers must maintain a low $\mathrm{F}_{1}$ through the 
stable laryngeal position described above, while raising $\mathrm{F}_{2}$. As studied by LoVetri ${ }^{7}$, this can be achieved with a higher tongue position, constricted pharyngeal walls, raised larynx, among others vocal tract shapes, all depending on the particular singer, character, and song context.

In belt voice, the smoothest sounding transitions were created not with formant frequency changes, but instead with vocal tract stability. This applied to all vowels. Maintaining a consistent vocal tract shape to allow these acoustic changes to take place naturally supports the concept of speech based singing. Noted CCM teachers Mary Saunders Barton and Matthew Edwards both encourage vocalizing using words and phrases to allow singers to connect emotions with different vocal sounds. ${ }^{8}$ Kenneth Bozeman advocates the use of affect and emotional states to access new resonances and shapes of the vocal tract. This matches suggestions by the subjects as to how they approach repertoire, and their acoustic differences between being asked to vocalize in belt, mix, or legit and sing a song excerpt support this method.

\section{AREAS OF FUTURE RESEARCH}

Terminology remains a problematic pedagogic puzzle piece. Though each singer was able to define and demonstrate quickly the terms in this study, all sounds were individual to the singer. With many teachers using the words belt and mix interchangeably, this leads to further confusion: S1's belt was not as “brassy" as S2's, but S1's mix was arguable stronger. Subtleties in the qualities possible with one word, like "belt" bring up a possible need for an MT voice

\footnotetext{
7 Jeannette L. LoVetri, "Contemporary Commercial Music: More than One Way to Use the Vocal Tract," Journal of Singing 58 (January 2002): 249-252.

${ }^{8}$ Matthew Edwards, So You Want to Sing Rock ' $n$ ' Roll: A Guide for Professionals (Lanham, Maryland: Rowman \& Littlefield, 2014).
} 
classification similar to the classical fach system. In a recent study published in the Journal of Singing, $62 \%$ of leading female roles in May 2014 were belt roles, $23 \%$ belt $/ \mathrm{mix}$, and $15 \%$ nonbelt. ${ }^{9}$ Not all belt is the same, however, for example, the belt voice used in The Lion King may not be the same as in Rock of Ages, and neither would be the same as Beautiful, or Violet, all listed as needing "belters" in their leading roles. Shows like If/Then and Les Miserables were listed as belt/mix shows, but many sounds are similar from these female roles to the ones listed as belt.

This project clearly demonstrates a difference between MT Legit and Western classical treble singing. A study aimed to clarify this difference would be useful for legit and Western classical singers who specialize in one or the other to help defend the need for a specific MT pedagogy. Belt and mix are different words that are felt differently, sound differently, and require further empirical scrutiny. Casting directors use these terms as separate styles, so therefore MT teachers must separate them. Further physiologic and aerodynamic data to differentiate MT Mix and Belt is needed to determine if mix can be classified as its own register, as some research has found, ${ }^{10}$ or simply a style of singing that uses acoustic changes to blend sound, as other research has defended. ${ }^{11}$ To continue research of acoustics between legit, mix, and belt, the data from the current study will be reanalyzed using long time average spectrum (LTAS), for considerations of a common "voice print" for these styles.

\footnotetext{
${ }^{9}$ Warren Freeman, Kathryn Green, and Philip Sargent, “Deciphering Vocal Demands for Today's Broadway Leading Ladies,” Journal of Singing 71, no. 4 (March-April 2015): 491-495.

${ }^{10}$ Karen Ann Kochis-Jennings, Eileen M. Finnegan, Henry T. Hoffman, and Sanyukta Jaiswal, "Laryngeal Muscle Activity and Vocal Fold Adduction During Chest, Chestmix, Headmix, and Head Registers in Females," Journal of Voice 26, no. 2 (March 2012): 182-93.

${ }^{11}$ Tracy Bourne and Maëva Garnier, "Physiological and Acoustic Characteristics of the Female Music Theater Voice," Journal of the Acoustical Society of America 131, no. 2 (February 2012): 1586-94.
} 


\section{Bibliography}

American Academy of Teachers of Singing. "In Support of Contemporary Commercial (nonclassical) Voice Pedagogy," 2008, http://www.americanacademyofteachersofsinging.org/assets/articles/CCMVoicePedagogy.pdf

Balog, Julie E. "A Guide to Evaluating Music Theater Singing for the Classical Teacher." Journal of Singing 61, no. 4 (April 2005): 401-6.

Barton, Mary Saunders. "Definitions and Thoughts on 'Belt," handout from "Music Theatre and the Belt Voice-II." National Association of Teachers of Singing Winter Workshop, New York, January 2001.

Bauer, Karen Tillotson. The Essentials of Beautiful Singing: A Three-Step Kinesthetic Approach. Lanham, Maryland: Scarecrow Press, 2013.

Bestebreurtje, Martine E., and Harm K. Schutte. "Resonance Strategies for the Belting Style: Results of a Single Female Subject Study.” Journal of Voice 14, no. 2 (June 2000): 194-204.

Bevan, Ronald Verle. "Belting and Chest Voice: Perceptual Differences and Spectral Correlates." Ed.D., Columbia University Teachers College, 1989.

Björkner, Eva. "Musical Theater and Opera Singing-Why So Different? A Study of Subglottal Pressure, Voice Source, and Formant Frequency Characteristics." Journal of Voice 22, no. 5 (September 2008): 533-40.

Björkner, Eva, Johan Sundberg, Tom Cleveland, and Ed Stone. "Voice Source Differences Between Registers in Female Musical Theater Singers.” Journal of Voice 20, no. 2 (June 2006): 187-97.

Boardman, Susan D. "Vocal Training for a Career in Music Theater: A Review of the Literature." NATS Journal 48, no. 5 (1992): 10-14.

Bourne, Tracy, and Maëva Garnier. "Physiological and Acoustic Characteristics of the Female Music Theater Voice.” Journal of the Acoustical Society of America 131, no. 2 (February 2012): 158694.

_. "Physiological and Acoustic Characteristics of the Female Music Theater Voice in 'Belt' and 'Legit' Qualities.” Proceedings of the International Symposium on Music Acoustics (Associated Meeting of the International Congress on Acoustics), Sydney and Katoomba, Australia, August 25-31, 2010. 
Bourne, Tracy, Maeva Garnier, and Diana Kenny. "Music Theater Voice: Production, Physiology and Pedagogy.” Journal of Singing 67, no. 4 (April 2011): 437-44.

Bozeman, Kenneth W. Practical Vocal Acoustics: Pedagogic Applications for Teachers and Singers. Hillsdale, NY: Pendragon Press, 2013.

Castellengo, M., B. Chuberre, and N. Henrich. "Is 'voix mixte' the vocal technique used to smooth the transition across the two main laryngeal mechanisms, or an independent mechanism?" Proceedings of ISMA, Nara, Japan, 2004.

Edwards, Matthew. So You Want to Sing Rock 'n' Roll: A Guide for Professionals. Lanham, Maryland: Rowman \& Littlefield, 2014.

Edwin, Robert. “Apples and Oranges: Belting Revisited.” Journal of Singing 57 (November 2000): 43-44.

—. "Belt Is Legit.” Journal of Singing 64, no. 2 (November 2007): 213-15.

—. "Belting 101.” Journal of Singing 55 (September 1998): 53-55.

—. "Belting 101, Part Two.” Journal of Singing 55 (November 1998): 61-62.

— . "Contemporary Music Theater: Louder Than Words." Journal of Singing 61, no. 3 (February 2005): 291-92.

Estill, Jo. "Belting and Classic Voice Quality: Some Physiological Differences.” Medical Problems of Performing Artists 3, no. 1 (1988): 37-43.

Freeman, Warren, Kathryn Green, and Philip Sargent. “Deciphering Vocal Demands for Today's Broadway Leading Ladies.” Journal of Singing 71, no. 4 (March-April 2015): 491-495.

Hall, Karen. So You Want to Sing Music Theater: A Guide for Professionals. Lanham, Maryland: Rowman \& Littlefield, 2014.

Henrich, Nathalie. "Mirroring the Voice from Garcia to the Present Day: Some Insights into Singing Voice Registers.” Logopedics Phoniatrics Vocology 31, no. 1 (February 2006): 3-14.

Kochis-Jennings, Karen Ann, Eileen M. Finnegan, Henry T. Hoffman, and Sanyukta Jaiswal. "Laryngeal Muscle Activity and Vocal Fold Adduction During Chest, Chestmix, Headmix, and Head Registers in Females." Journal of Voice 26, no. 2 (March 2012): 182-93. 
Lawrence, V. “Laryngological Observations on 'Belting.”” Journal of Research In Singing, 1979.

LeBorgne, Wendy DeLeo, Linda Lee, Joseph C. Stemple, and Heather Bush. "Perceptual Findings on the Broadway Belt Voice.” Journal of Voice 24, no. 6 (November 2010): 678-89.

Lebowitz, Amy, and R. J. Baken. "Correlates of the Belt Voice: A Broader Examination.” Journal of Voice 25, no. 2 (March 2011): 159-65.

LoVetri, Jeannette L. "The Confusion About Belting: A Personal Observation.” NYSTA Voice Prints 10 (September-October 2012): 4-7.

—. "Contemporary Commercial Music.” Journal of Voice 22, no. 3 (May 2008): 260-62.

—. "Contemporary Commercial Music: More than One Way to Use the Vocal Tract." Journal of Singing 58 (January 2002): 249-52.

—. "Female Chest Voice.” Journal of Singing 60, no. 2 (December 2003): 161-64.

LoVetri, Jeannette L, and Edrie Means Weekly. "Contemporary Commercial Music (CCM) Survey: Who's Teaching What in Nonclassical Music.” Journal of Voice 17, no. 2 (June 2003): 207-15.

LoVetri, Jeannette, Susan Lesh, and Peak Woo. "Preliminary Study on the Ability of Trained Singers to Control the Intrinsic and Extrinsic Laryngeal Musculature." Journal of Voice 13, no. 2 (June 1999): 219-26.

McCoy, Scott. “A Classical Pedagogue Explores Belting.” Journal of Singing 63, no. 5 (June 2007): 545-49.

—. "Why I Don’t Teach Belting.” Journal of Singing 70, no. 2 (November/December 2013): $181-182$.

- Your Voice: An Inside View, $2^{\text {nd }}$ ed. Delaware, OH: Inside View Press, 2012.

Miles, Beth, and Harry Hollien. “Whither Belting?” Journal of Voice 4, no. 1 (1990): 64-70.

Miller, Donald G. Resonance in Singing: Voice Building through Acoustic Feedback. Princeton, NJ: Inside View Press, 2008.

Miller, Donald G., and Harm K. Schutte. "Mixing the Registers: Glottal Source or Vocal Tract?" Folia Phoniatrica et Logopaedica 57, no. 5-6 (2005): 278-91. 
Phyland, Debra J., Susan L. Thibeault, Michael S. Benninger, Neil Vallance, Kenneth M. Greenwood, and Julian A. Smith. "Perspectives on the Impact on Vocal Function of Heavy Vocal Load Among Working Professional Music Theater Performers.” Journal of Voice 27, no. 3 (May 2013): 390 .

Popeil, Lisa. “The Multiplicity of Belting.” Journal of Singing 64, no. 1 (October 2007): 77-80.

Robison, Clayne W., Barry Bounous, and Ross Bailey. "Vocal Beauty: A study proposing its acoustical definition and relevant causes in classical baritones and female belt singers." NATS Journal 51, no. 1 (1994): 19-30.

Roubeau, Bernard, Nathalie Henrich, and Michèle Castellengo. "Laryngeal Vibratory Mechanisms: The Notion of Vocal Register Revisited.” Journal of Voice 23, no. 4 (July 2009): 425-38.

Schutte, Harm K., and Donald G. Miller. "Belting and Pop, Nonclassical Approaches to the Female Middle Voice: Some Preliminary Considerations.” Journal of Voice 7, no. 2 (June 1993): 14250.

Spivey, Norman. "Music Theater Singing...Let's Talk. Part 2: Examining the Debate on Belting." Journal of Singing 64, no. 5 (June 2008): 607-14.

—. "Teaching Music Theater Singing: One Teacher's Journey." Journal of Singing 62, no. 2 (December 2005): 199-202.

Stone, R.E, Thomas F Cleveland, Johan Sundberg, and Jan Prokop. "Aerodynamic and Acoustical Measures of Speech, Operatic, and Broadway Vocal Styles in a Professional Female Singer." Journal of Voice 17, no. 3 (September 2003): 283-97.

Sullivan, Janet. "How to Teach the Belt/Pop Voice." Journal of Research In Singing \& Applied Vocal Pedagogy, 1989.

Sundberg, Johan. The Science of the Singing Voice. Dekalb, IL: Northern Illinois University Press, 1987.

Sundberg, Johan, Patricia Gramming, and Jeannette L. LoVetri. "Comparisons of Pharynx, Source, Formant, and Pressure Characteristics in Operatic and Musical Theatre Singing." Journal of Voice 7, no. 4 (1993): 301-10.

Sundberg, Johan, Margareta Thalén, and Lisa Popeil. "Substyles of Belting: Phonatory and Resonatory Characteristics." Journal of Voice 26, no. 1 (January 2012): 44-50. 
Titze, Ingo. "Belting and a High Larynx Position." Journal of Singing 63, no. 5 (May-June 2007): 557-558.

. "Formant Frequency Shifts for Classical and Theater Belt Vowel Modification." Journal of Singing 67, no. 3 (February 2011): 311-12.

Principles of Voice Production. Englewood Cliffs, N.J: Prentice Hall, 1994.

Titze, Ingo, Albert S. Worley, and Brad H. Story. "Source-Vocal Tract Interaction in Female Operatic Singing and Theater Belting." Journal Of Singing 67, no. 5 (May-June 2011): 561-572.

Weekly, Edrie Means, and Jeannette L. LoVetri. "Follow-Up Contemporary Commercial Music (CCM) Survey: Who's Teaching What in Nonclassical Music." Journal of Voice 23, no. 3 (2009): 367-75.

Yanagisawa, Eiji, Jo Estill, Steven T. Kmucha, and Steven B. Leder. "The Contribution of Aryepiglottic Constriction to 'Ringing' Voice Quality - A Videolaryngoscopic Study with Acoustic Analysis." Journal of Voice 3, no. 4 (1989): 342-50. 


\section{Appendix 1: Survey}

Personal Information (to be answered prior to singing):

Age:

Do you currently have any diagnosed voice injury or disorder?

Years of Professional Performance Experience:

Name 3 roles performed within the last 2 years:

Training:

Western Classical Music: yes / no Years:

Contemporary Commercial Music (CCM) / Music Theatre (MT): yes / no Years:

If yes, was any of your CCM / MT training at a college or university? yes / no

If yes, was your teacher trained in CCM / MT styles, or did your

teacher have professional CCM/MT experience? yes / no / don't know

How would you perceptually describe "belt" voice regarding sensation and production?

How would you perceptually describe "legit" voice regarding sensation and production?

How would you perceptually describe "mix" voice regarding sensation and production?

Perception Questions (to be answered after the exercises):

Describe what you felt or did differently in the "belt" exercises compared to the "legit" exercises. For example, what did you feel or do in your throat and larynx? In your head and face? In your articulators (tongue, jaw, soft palate, etc.) If you felt no change, say so.

When singing in the "mix" exercises, was what you felt or did more similar to the "belt" exercises, the "legit" exercises, or was it unique to itself? 


\section{Appendix 2: Informed Consent}

\section{Only Minimal Risk \\ Consent Information Form (without HIPAA)}

Principal Investigator Nicholas Perna

Department Music

Protocol Number 1503619715

Study Title The Relationship between Kinesthetic Perceptions of Elite Music Theater Singers and Acoustic Measures of Voice Production Methods: A Pedagogic Analysis

Co-Investigator(s) Leigh Usilton

Sponsor (if any) none

\section{Contact Persons}

In the event you experience any side effects or injury related to this research, you should contact Nicholas Perna at 304-293-4537.(After hours contact: Nicholas Perna at 786-269-4841.

For information regarding your rights as a research subject, to discuss problems, concerns, or suggestions related to the research, to obtain information or offer input about the research, contact the Office of Research Integrity \& Compliance at (304) 293-7073.

In addition if you would like to discuss problems, concerns, have suggestions related to research, or would like to offer input about the research, contact the Office of Research Integrity and Compliance at 304-293-7073.

\section{Introduction}

You [Participant] have been asked to participate in this research study, which has been explained to you by Leigh Usilton. This study is being conducted by her in the Department of Music at West Virginia University.

\section{Purpose(s) of the Study}

This study will compare the kinesthetic feedback of professional music theater singers to acoustic data for the purpose of developing vocabulary useful for voice teachers.

\section{Description of Procedures}

1. You will first be asked a series of questions regarding your professional performance experience and training. You will then be asked questions addressing your physical perception of "belt," "legit," and "mix" voice. Your responses will be recorded using a passcode protected Samsung Galaxy S5, and uploaded onto a password protected HP laptop.

2. Following the interview, you will sing an ascending C major scale four times in "legit" voice on the vowels /a/ as 
in "father", /æ/ as in "cat", / $\varepsilon /$ as in "let", and /っ/ as in "bought" respectively. An E-flat major scale with the same four vowels will follow. The scales will be repeated next in "belt" voice, and lastly in "mix." All scales will be recorded using VoceVista software, version 3.3, on a password protected HP laptop.

3. Following the scales, you will sing the brief excerpts provided to you: measures 71 to 76 from "There's a Fine, Fine Line" from Avenue Q, measures 90 to 97 in "Gimme Gimme" from Thoroughly Modern Millie, and the last five measures from "The Wizard and I" from Wicked. All excerpts will be recorded using VoceVista software, version 3.3, on a password protect HP laptop.

4. Lastly, you will be asked a series of questions regarding your comparative kinesthetic feedback in belt, legit, and mix in the previous scales.

It will take approximately 30 minutes for you to complete. You do not have to answer all the questions. You will have the opportunity to see the questionnaire before signing this consent form.

\section{Discomforts}

There are no known or expected risks from participating in this study.

\section{Benefits}

You may not receive any direct benefit from this study. The knowledge gained from this study may eventually benefit others.

\section{Financial Considerations}

There are no special fees for participating in this study.

You will be compensated with a \$10 Starbucks gift card for participation in this study.

\section{Confidentiality}

Any information about you that is obtained as a result of your participation in this research will be kept as confidential as legally possible. Your research records and test results, just like hospital records, may be subpoenaed by court order or may be inspected by the study sponsor or federal regulatory authorities (including the FDA if applicable) without your additional consent.

In addition, there are certain instances where the researcher is legally required to give information to the appropriate authorities. These would include mandatory reporting of infectious diseases, mandatory reporting of information about behavior that is imminently dangerous to your child or to others, such as suicide, child abuse, etc.

Audiotapes or videotapes will be kept locked up and will be destroyed as soon as possible after the research is finished. In any publications that result from this research, neither your name nor any information from which you might be identified will be published without your consent.

\section{Voluntary Participation}

Participation in this study is voluntary. You are free to withdraw your consent to participate in this study at any time.

Refusal to participate or withdrawal will involve no penalty to you. 
In the event new information becomes available that may affect your willingness to participate in this study, this information will be given to you so that you can make an informed decision about whether or not to continue your participation.

You have been given the opportunity to ask questions about the research, and you have received answers concerning areas you did not understand.

Upon signing this form, you will receive a copy.

I willingly consent to participate in this research.

\section{Signatures}

Signature of Subject

Printed Name

Date

Time

The participant has had the opportunity to have questions addressed. The participant willingly agrees to be in the study.

Signature of Investigator or Co-Investigator

Printed Name

Date

Time 


\section{Appendix 3: IRB Approval Letter}

\section{W.WestVurginiaUniversity. \\ Office of Research Integrity and Compliance \\ Approval Letter Expedited}

To

From

Action Date

Approval Period

Subject

Protocol Number

Title
Nicholas Perna

WVU Office of Research Integrity and Compliance

03/30/2015

03/30/2015 Expiration Date 03/29/2016

Protocol Approval Letter

1503619715

The Relationship of Kinesthetic Perception of Elite Music Theater Singers and Acoustic Measures of Voice Production Methods: A Pedagogic Analysis

The above-referenced research study was reviewed by the West Virginia University Institutional Review Board IRB and was approved in accordance with 46 CFR $46.101 \mathrm{~b}$.

It has been determined that this study is of minimal risk and meets the criteria as defined by the expedited categories listed below:

- $\quad$ This is an expedited category 6 and 7.

Documents for use in this study are available in the WVUkc system in the Notes and Attachments section of your protocol.

The Office of Research Integrity and Compliance is here to provide assistance to you from the initial submission of an IRB protocol and all subsequent activity. Please feel free to contact us by phone at 304.293.7073 with any question you may have. Thank you.

WVU Office of Research Integrity and Compliance

Date: $03 / 30 / 2015$

Signed:

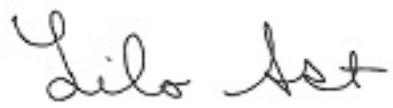

Lilo Ast

Senior Program Coordinator 


\section{Appendix 4: Interview Transcripts}

\section{S1 Interview}

\section{Part I}

Investigator (LU): The following three questions relate to how you personally sense, and therefore define, terms often used in music theater singing. First, how would you perceptually describe "belt" voice regarding sensation and production? For example, what do you feel or do in your throat and larynx? In your head, face, or chest? In your articulators? (tongue, jaw, soft palate, etc.)

S1: I think of belting as, as high and forward. Um, I actually think of most things as high and forward. And um, I don't differentiate too much between belting and mixing, I guess the only difference for me is, um, if I know where the notes are I kind of, um, know how much higher and how much more forward I'm going to go. Does that make sense?

LU: Yes it does. So similarly, how would you perceptually describe "legit" voice regarding sensation and production?

S1: $\quad$ For a legit sound, I think in terms of far more open, um, again, I do it all in a like, high... and rather than high and forward nasally, when I think of legit I think of more high and up. More like up through the top of my head, I guess. Um, I... [laughs] trying to figure it out [she makes different mouth shapes and sounds]. Yeah, I guess it's the difference between coming up through my nose versus coming up through, um, like a wide, open, um, palate. [while gesturing up towards her forehead]

LU: Lastly, how would you perceptually describe "mix" voice regarding sensation and production?

S1: For me a mix voice is closest to how I talk, so, um, I think about it least of all and um, again I just think relaxed, open, high, and forward. In my palate, and in my breath, like up and around [again gesturing up towards her forehead] Hahaha, it sounds so ridiculous! Haha, it's hard to describe.

\section{Part II}

LU: Describe what you felt or did differently in the belt exercises compared to the legit exercises. For example, what did you feel or do in your throat and larynx? In your head, face, or chest? In your articulators (tongue, jaw, soft palate, etc.)? If you felt no change, say so.

S1: Well, it's interesting. When I'm not making words, I don't think about it too much. Um, I just kind of go where it feels comfortable. And, there's an openness to my throat and the back of 
my throat specifically when I'm thinking in a more legit sound [she demonstrates on /a/, 5 note scale ascending quickly], like it's just an openness and a high and above feeling when I'm singing in a more legit, um, sound. And then when I'm doing the scales in a more belty or mix way I don't feel like there's too much of a difference that I think about, um again it just feels, um, high and placed more in my nose, um, more towards the front I guess rather than up and around.

LU: $\quad$ As the legit voice.

S1: Yeah.

LU: When singing in the mix exercises, was what you felt or did more similar to the belt exercises, the legit exercises, or was it unique to itself?

S1: You know, it's interesting. Even though I know the sound sounds very different, what I'm doing doesn't feel so different between all three of them actually. Um, but the belting and the mixing certainly feel more closely related than the legit sounds. Um, when I think of how I breathe and how I hold my face or my head, I don't feel that much of a difference. Um, I know I talk a lot about, uh, either openness or feeling things higher and then forward, that's the biggest difference that I can describe, I don't think about it too much, um, as like a different approach. Is that ok?

LU: $\quad$ Is there anything else you would like to say...?

S1: Um, well, you know it's so, it's...the second you put down something like "The Wizard and I" there's, um, a placement that's different from anything that I did, uh, in the exercises? I don't know why that is. Um, I think it probably has to do with vowels, but when you're making words it makes it easier to kind...to, um, to choose? Than it does when it's just on a vowel. Um, 'cause I noticed that like the kind of belting I was doing, uh, at the end of that song was completely different from what I was doing in the belting scales, when I'm thinking about it. Um, and I, I'm assuming it has to do with words, context, previous knowledge of the song, um, and that's no higher than any of the ones we sang in the scales, but, that's just something that I, that I noticed. These ones where I, where it's more mixy it feels consistent, but you know, you get handed this and you know what they want to hear, and it's...so that.

LU: Did it feel like there was more effort? Or just different?

S1: [she sings "The Wizard and I" sample again] It just feels, um, [pause] it feels, uh, just, more, even more forward and more nasal and, um, it does feel a little harsher, um

LU: Tonally?

S1: Yeah. And also again you're talking about a straight tone versus, um, if you were singing from Oklahoma and belting it's a different, you know, if I'm singing "I Can't Say No" it's a 
different belt than this one, would be where I know that they're gonna be like "straight-tone, straight-tone, straight-tone" so all of a sudden it's not [sings "The Wizard and I" twice, first with and next without vibrato]. You straighten it as much as you can which automatically puts it in a, um, more, uh, nasal and aggressive [laughs] place, for lack of a better word. That's what I noticed. 


\section{S2 Interview}

\section{Part I}

LU: The following three questions relate to how you personally sense, and therefore define, terms often used in music theater singing. First, how would you perceptually describe "belt" voice regarding sensation and production? For example, what do you feel or do in your throat and larynx? In your head, face, or chest? In your articulators? (tongue, jaw, soft palate, etc.)

S2: Um, I guess I normally, it's like that ping, so I feel it, like here in my [she points to her sinus cavities, below her eyes]. Um, like where I try to place it I guess?

LU: Yes, how do you sense it.

S2: Um, yeah, I feel like when I try to place it it's more of like, a ping, like it's a more forward sound rather than like, down, than like a chesty sound, if it's a really high belt. Yeah. I would say that it comes more from the, it's like from a forward place rather than like a throaty place or like a deep chest place. I don't ever really feel anything [in the throat], so I guess that's a good sign, I mean it doesn't hurt. It never hurts or anything. So, I guess I feel like for me personally, it's more of like, it's more in like a mix placement and it's just a bigger sound.

LU: So similarly, how would you perceptually describe "legit" voice regarding sensation and production?

S2: Um, that is all just like falsetto, soprano for me. I mean, I'm more of like a belter, so soprano, like, isn't my thing, but it's definitely like that "ah!" [demonstrates] you know what I mean, that very, also like very forward sound. I mean, I can't imagine any one like really singing, like legit, like through their throat, you know what I mean? So I guess it's also just a very forward sound.

LU: Lastly, how would you perceptually describe "mix" voice regarding sensation and production?

S2: Um, I feel like a mix sound is probably the easiest. But, I, you know, I think, it depends on like the range of the mix. You know, it depends on like the range of the mix. I feel like if you're kind of, if you're singing in a lower register but it's not a full belt, it's just a mix, I feel like it could still, it could be from that chesty place. But I mean, I think as you get higher, like as the range gets higher, you're sitting in that like, lighter place, that's not necessarily airy or breathy, it's a higher register so it's a lighter...it's like a more, it's a forward place. 


\section{Part II}

LU: Describe what you felt or did differently in the belt exercises compared to the legit exercises. For example, what did you feel or do in your throat and larynx? In your head, face, or chest? In your articulators (tongue, jaw, soft palate, etc.)? If you felt no change, say so.

S2: Um, in the belt, I definitely was in that forward place like I talked about earlier, um, I just felt like the resonance here, in that sinus zone that cheek zone, and um...that was different from the legit because, I actually feel now that I did it, um, it's more in like the throat. The "ah" [sings high in legit]. It's not really, like as you get higher I think you would place it, you know, a little bit more forward, but it is in that...that, you feel it in your throat place.

LU: In the legit exercises?

S2: Yeah, the legit exercises, yeah.

LU: When singing in the mix exercises, was what you felt or did more similar to the belt exercises, the legit exercises, or was it unique to itself?

S2: Um, I think it was unique in itself, because it became a blend of both. So, um, [pause] like in some of the belt exercises, I think for me there's like that break where I then mix, but like still push, not like push in a bad way, but so it sounds more like a belt. But, um, I think it's kinda the same way, with that mix that's like I sit in that kind of belty place but it's just like soft, you know? And then as I get higher, especially on like the Eb scales I think it flips into that little bit more like a legit place for the higher notes? So...does that make sense?

LU: Yes it does! So when you say it flips into that legit, does that mean it flips more into the throat sensation you described?

S2: I think so yeah. I think it would go, as like, you go up the scale it kind of goes from that chesty place into that throaty place, since it's not like a full belt on those high notes, you know, and it's that more of like, since it's softer I feel like it has that more, like, legit sound. Even though it's still a mix. 


\section{S3 Interview}

\section{Part I}

LU: The following three questions relate to how you personally sense, and therefore define, terms often used in music theater singing. First, how would you perceptually describe "belt" voice regarding sensation and production? For example, what do you feel or do in your throat and larynx? In your head, face, or chest? In your articulators? (tongue, jaw, soft palate, etc.)

S3: The way I think about it is very simplistic, um, it's not scientific in any way, but I feel like belt voice is, um, putting pitch on my speaking voice, and making it really forward. That's how I think about belting.

LU: $\quad$ Forward in...

S3: $\quad$ In my mask. Forward in the mask.

LU: So similarly, how would you perceptually describe "legit" voice regarding sensation and production?

S3: Legit voice seems like a more natural singing voice to me, again I'm not a scientific person in any way. Legit voice is simply to me what comes out when I'm singing naturally. So, um, it's how I first started to sing as well, so I think that's probably very connected. I didn't belt until probably I was in my mid-20s, and I taught myself to belt, uh, from listening to people that did that, so, yeah, I think that that's just sort of what I thought singing was for the longest time so that's what naturally comes out unless I make the conscious decision to belt. So, I probably haven't really answered your question very well.

LU: No you have! The question is about how you perceive it, there's no right or wrong.

S3: I perceive it to be easier than belting, um, I don't get tired as quickly, so yeah. And it keeps my belt healthy. If I have to do a show where I belt I always reset into my head voice and that keeps me well-going for the depth of the run.

LU: Lastly, how would you perceptually describe "mix" voice regarding sensation and production?

S3: A mix, also very far forward in the mask, and just with a little, with a little more chest voice added in. For me. 


\section{Part II}

LU: Describe what you felt or did differently in the belt exercises compared to the legit exercises. For example, what did you feel or do in your throat and larynx? In your head, face, or chest? In your articulators (tongue, jaw, soft palate, etc.)? If you felt no change, say so.

S3: Um, there is more air in my belt, um, more breath needed for belting. Um, I would say that my larynx, depending on where the belt is happening, but the higher the belt goes the larynx is definitely higher. Um, my tongue drops more, um, for belting, than it needs to in legit. Uh, I'm always more aware of where my tongue is when I'm belting, honestly, um, than I am in legit voice. I don't think about it as much, but I think that's because, it just, it's so natural for me to do the other, and I think more about the belt. Um, I did do some straight-tone belting, and I do feel pressure in my neck, um, when I need to straight-tone I can't let that vibrato in. Uh, am I answering your question?

LU: Yes.

S3: $\quad$ Do I need to expound?

LU: Well, when you say pressure, is that it muscle? Or actual air pressure?

S3: In muscle, tightness... a little tightness. I'm not tired, it does not hurt in any way, I just feel more, there's the, uh, more of a sensation that I'm aware of my neck than, um, than I am when I'm singing in legit voice. Just an awareness.

LU: When singing in the mix exercises, was what you felt or did more similar to the belt exercises, the legit exercises, or was it unique to itself?

S3: It was very unique, and I think that I haven't mixed a lot lately so I actually was far more challenging than either of the, um, legit or belt for me, which is really interesting because I actually used to be, like, a really great mixer. So, I haven't been called on to do that, um, I had to think really hard about it. Um, different vowels were easier than others. Um, brighter vowels were certainly easier to get the mix I think, I felt. As far as sensation goes, I was way more conscious of switching, um, registers in my mix voice, and um, than I was in anything else. Um, so yeah, that was kind of interesting. Very comfortable feeling, like, it all felt great, like, once I found it I was thrilled that it was still there [laughs], but she was hard to find! [laughs]

LU: So when you mentioned the switching that you felt throughout the exercises, again, did it feel like you were switching on the spectrum of belt to legit? Or was it still staying in its own world?

S3: I feel like if I was, um, I feel like, actually, I switched from legit into mixing, is how I thought about this, which, I didn't feel like I was, um, I wasn't conscious of being switched into 
belting, persay, it just is a different, mix to me is just a much, much brighter, almost more nasal sound than either $m y$ legit or $m y$ belt. A lot of people belt nasal, and I actually don't think that I'm a nasal belter, but I think I am a nasal mixer. [laughs]

LU: Is there anything else that you experienced, or would like to say about what you just sang?

S3: I'm just all, sort of fascinated to sort of sit down and think about things more deeply than I.... just sort of sing and the voice goes where it goes, so it's been a long time since I sort of thought about compartmentalizing the sounds, and words. Yeah, yeah! It was interesting! I can't wait to sort of see how this turns out. 


\section{S4 Interview}

\section{Part I}

LU: The following three questions relate to how you personally sense, and therefore define, terms often used in music theater singing. First, how would you perceptually describe "belt" voice regarding sensation and production? For example, what do you feel or do in your throat and larynx? In your head, face, or chest? In your articulators? (tongue, jaw, soft palate, etc.)

S4: I'm a firm fan of the mask singing. When I belt personally, I go through my, like, sinus resonators, um, to get a clearer, healthier belt. That's what I rely on as opposed to really feeling throat or larynx things happening, 'cause I find that when I do there I end up doing like the "bark." So I think more...less Idina Menzel and more Sutton Foster I guess in my school for that. Yeah, definitely more forward. Um, when I'm super warmed up or have remnants of a cold [points to the top of her forehead], that where I just really, it's really where I feel it. I'm thinking more through like, my face.

LU: So similarly, how would you perceptually describe "legit" voice regarding sensation and production?

S4: Uh legit voice, uh, the dropping of the larynx, um, I feel it more, I mean and the raising of the soft palate, and so I feel more going up like behind my ears? As opposed to forward in my face, I find it more in like, the central cavity of my, head.

LU: You mentioned the dropping of the larynx. Does that mean you feel it higher in belt?

S4: Uh, yes, personally I do.

LU: Lastly, how would you perceptually describe "mix" voice regarding sensation and production?

S4: Uh, I, it's a marriage of the two. Um, I find more freedom in my vibrato in my mix voice. As compared to really moving in legit because of space, or really straight-toning in belting. Um, I find that that's my happy place, and uh, it's a mixture of the space and the mask for me.

\section{Part II}

LU: Describe what you felt or did differently in the belt exercises compared to the legit exercises. For example, what did you feel or do in your throat and larynx? In your head, face, or chest? In your articulators (tongue, jaw, soft palate, etc.)? If you felt no change, say so.

S4: Um, belt, for me is uhhh, more natural straight tone. Uh, I don't feel like I'm forcing it, but I just, my brain makes me straight tone more. Um...[pause] 


\section{LU: And do you feel that anywhere?}

S4: I feel it kind of, like, flat...again in my, haha, I'm making a face right now [she's scrunching her nose and drawing a horizontal line just above her chin]. Um, I feel it...I feel it moving horizontally out as opposed to vertically out in my cavities.

LU: In your oral cavities? Your sinus cavities...?

S4: Yeah. All of the above. Yes. That is how I feel. [laughs]

LU: When singing in the mix exercises, was what you felt or did more similar to the belt exercises, the legit exercises, or was it unique to itself?

S4: I find it unique to itself. The, uh, mix is my happy place. That is what, like, vocally, like, without me trying to, like, play mind games, and like open my mouth and sing that is how I sing, so I find that to be, um, the easiest, and less stress. 'Cause I find that's more my natural voice, whereas when I'm singing legit I'm applying something, and when I'm belting I'm also applying something.

LU: So, with your natural voice, that means, maybe, closer to your speaking voice?

S4: Closer to my speaking voice, yeah. Closer to my speaking voice, just, like, without any editing, or like left brain, like, singing stuff happening. It's my, it's my mix voice.

LU: And is there anything else that you noticed or would like to comment on about the experience?

S4: Uh, that singing scales for just the sake of singing scales is really strange when it's not, like, a warm-up situation? And like when that is the "performance" of it, um, yeah, very mechanical, very odd just to be singing scales for scale's sake. Yeah, and kinda...not necessarily being a slave to time, but, like, doing it slowly and not really having to sustain it on the breath. Yeah, strange. 


\section{S5 Interview}

\section{Part I}

LU: The following three questions relate to how you personally sense, and therefore define, terms often used in music theater singing. First, how would you perceptually describe "belt" voice regarding sensation and production? For example, what do you feel or do in your throat and larynx? In your head, face, or chest? In your articulators? (tongue, jaw, soft palate, etc.)

S5: Uh, I guess when I am belting, when I find a good spot, I feel, I don't feel very much in my throat. Um, I feel resonance in my chest, but I feel a relaxed sensation in my throat and on the back of my tongue, if I find a good spot. Um, and in my nose, definitely. Especially if it's like, uh, a nice ping-y mix-belt, definitely a lot of resonance, a lot of buzzing here [points], in my mask.

LU: So similarly, how would you perceptually describe "legit" voice regarding sensation and production?

S5: Um, I feel a more hollow, open feeling in the back of my throat and the, like going up into my nose, I guess. Um, it feels much more open than when I'm belting. Um, it's definitely breathier. With me, I feel a lot of breath, but I don't have a very trained legit voice. Um, it's less pressure...pressure is the wrong word...it feels, um, for me personally, like I do need to put a little bit more, um, I use my throat a little bit more, but I think that's because I try to create a sound that's not breathy. It's more difficult for me definitely.

LU: Lastly, how would you perceptually describe "mix" voice regarding sensation and production?

S5: Um, the easiest. The most effortless. I feel the least resonance when it's happening, I feel like, I don't feel a lot of, I feel buzzing in my mask. I don't feel too much happening in my throat and chest, not like when I have, like, a nice pure chest belt going on. Um, I guess like a nice flat tongue, um, but once I'm in that ping-y spot, that mix-belt, it's pretty effortless. It feels like not, I don't feel a lot of vibration.

\section{Part II}

LU: Describe what you felt or did differently in the belt exercises compared to the legit exercises. For example, what did you feel or do in your throat and larynx? In your head, face, or chest? In your articulators (tongue, jaw, soft palate, etc.)? If you felt no change, say so.

S5: I felt like in the legit versus the belt, uh, with the legit I felt a higher soft palate, like a bigger egg in my mouth. I felt more tension in my throat, um, and with the belt I felt much more resonance in my chest. I felt, um, like I used more breath. 
LU: When singing in the mix exercises, was what you felt or did more similar to the belt exercises, the legit exercises, or was it unique to itself?

S5: I think I was much more similar to belt, although the higher extremes, like closer to the high Eb's, felt a little closer to the legit, or like a head mix. If that makes sense.

LU: Absolutely. And just to clarify how you felt the belt, the mix, and the legit, since you said your mix is usually closer to belt, what does that feel like?

S5: Um, it feels like [she hums], it's so hard to describe! [makes more sounds] Um, it feels like it sits higher, like almost, almost like behind my nose as opposed to like where my vocal cords are...like it kind of sits on top of them.

LU: Which one?

S5: The mix. Yeah, I guess that's how I would describe it. I feel less vibration in the mix. Expecially the high, high mix. It almost feels like nothing's happening.

LU: Do you feel any more or less tension in the others? You said in legit you felt a lot more.

S5: Yeah. I feel more tension in extreme highs in the mix. Here. [she points to her throat]

LU: Is there anything else you discovered or felt while doing the exercises?

S5: I discovered my happy vowels! Um, my happy vowels are aw as in bought. I discovered I don't like /ae/ very much in a belt...or was it E...it was E. Um, yeah. No fun. What did I tell you I discovered...I was supposed to remember it...[she laughs]

LU: When you were switching? When we were doing the Eb belt exercise, maybe a specific vowel?

S5: Oh, the switch was, oh, it was harder with my mix when we were in the C scale, it was hard to start in like a low mix, and not naturally go to like a pure belt. My mix down low, my mix under like $\mathrm{a} \mathrm{Bb}$ is hard to find I think.

LU: Anything else?

S5: Nothing I can think of right now. It was, it's been a while since I've had a proper voice lesson, so definitely checking in with my body as it's growing and...it was eye opening. 


\section{S6 Interview}

\section{Part I}

LU: The following three questions relate to how you personally sense, and therefore define, terms often used in music theater singing. First, how would you perceptually describe "belt" voice regarding sensation and production? For example, what do you feel or do in your throat and larynx? In your head, face, or chest? In your articulators? (tongue, jaw, soft palate, etc.)

S6: Belt voice is almost like, I feel like it's almost like singing with your speaking voice, that's on a pitch. Um, your range is, I think it's a lot more limited. I'm also not a belter, so it's kind of hard for me. Um, it's almost harsher, or it's a little more...I don't know how to describe it...I would mostly just say it's kind of like singing on your speaking voice, with more support.

LU: So similarly, how would you perceptually describe "legit" voice regarding sensation and production?

S6: Um, legit voice, how do I describe legit voice?

LU: Yes, how do you sense it.

S6: Yeah, I feel a little more like space, more resonance throughout my, like, head and my throat feels more open.

LU: More open than belt voice?

S6: Yes. It's almost like a dome when I'm in head voice, and in belt it's more like, like a little flatter. And a mix is somewhere in the middle. That's, uh, the way that I see things [laughs]. Legit is more head voice, belt is more chest voice.

LU: Lastly, how would you perceptually describe "mix" voice regarding sensation and production?

S6: Mix is just a thing, I still can't figure out, but for me mixing is kinda like what Kelli O'Hara did in Light in the Piazza. It's very like, um, it's more of a flat tone, but with, in the higher register? So it's like a head voice, but it's, it's almost more of a musicality, I think.

LU: So not necessarily a specific sensation, but a product?

S6: Yeah. And it's a little more like your tongue has to be placed differently. It's like you're singing in your head voice but you're, you're just like you're a little flatter I guess? Like the roof of your mouth is flatter, it's not as like, open and resonant. It's like more nasal and placed forward. [places her hands at her mouth, flat and parallel to each other to demonstrate shape] Laughs. Like belt is very forward and nasal and then legit, mix is in the middle and legit is more open and resonant and circular, kind of. Dome-y. 


\section{Part II}

LU: Describe what you felt or did differently in the belt exercises compared to the legit exercises. For example, what did you feel or do in your throat and larynx? In your head, face, or chest? In your articulators (tongue, jaw, soft palate, etc.)? If you felt no change, say so.

S6: Um, when I was in belt it was definitely a chest voice. It was very much my speaking voice, and, um, my larynx, I think, went high? Went up? Which I don't think is good. [laughs] But I think it went up, and, um, my palate, um, flattened, instead of, yeah, the dome.

LU: Though you feel the dome and the palate raise when you're singing legit?

S6: Yeah.

LU: When singing in the mix exercises, was what you felt or did more similar to the belt exercises, the legit exercises, or was it unique to itself?

S6: Definitely legit. Yeah. I don't, um, there is a mix that I've never been able to figure out, [laughs] that's mixy belt that I just can't, I can't figure that out. But, for me a mix is very much, my mix is very much legit.

LU: The mix-belt that you're trying to figure out, that's a sound that you hear and you're trying to recreate?

S6: Yeah. I feel like a lot of singers, I don't know... especially like the girls who sing Elphaba or whatnot, like, most of that's mix. Because you can't, most people can't belt that every night, you know. So, and a lot of just, so it's like lighter, super pingy mixes that's, like, so nasal, like placed perfectly, that's a mix I've never been able to find. But that sounds more belty, I guess. I think there's like a mixy belt and then there's a mixy legit. I would be definitely much more legit.

LU: Is there anything else that you'd like to say? Anything that you experienced?

S6: I think my biggest comment is that I've learned so, it's become so apparent to me that when you are singing every day, it's just like when you're working out every day you become so much stronger? And especially with mix, like the mix-legit. I haven't done that in over...at least half a year, you know. So, like, I feel like it's so weakened.

LU: $\quad$ So you did that in your last show?

S6: It was very, very legit. Yeah. I was very, like, high..I lived, like, high, like up here [plays on the piano]. More than down here [points to the lower end of the piano]. So, you know. Um, so, and every register, the more you do it, if you do it every day then you're gonna be so much better at it every day. And that's so obvious, like practice, of course, but your voice is naturally placed there if you sing it for, like, a week you're gonna...I barely, I don't even, like need to 
warm up sometimes if I am singing it consistently every day healthily, you know. So, like, I'm at a place right now I haven't really sung in a couple months...except for, like, some ensemble things, and you know. Um, for me as a singer that's so bad! [laughs] But, it, I, you just feel such a difference, like a dancer who doesn't dance, like you don't, your body just feels different. So, that's my biggest, especially from this, I'm like, "Oh god." This sounds completely different from what I'm used to. But, at the same time, like, it's a study, you know? Because I haven't been doing it every day. I've been doing it even more than once a week. At my home, like whenever I'm alone I can sing myself. That's my biggest comment, um, I think. Because that's something that was so apparent to me. 